\title{
Synthesis and Anti-HIV Activity of ${ }^{-}$- and $\mathrm{L}_{\mathrm{L}}$-Thietanose Nucleosides
}

\author{
Hyunah Choo ${ }^{1}$, Xin Chen ${ }^{1}$, Vikas Yadav ${ }^{1}$, Jianing Wang ${ }^{1}$, Raymond F. Schinazi ${ }^{2}$, and Chung \\ K. $\mathrm{Chu}^{1}{ }^{1}{ }^{*}$ \\ 1The University of Georgia, College of Pharmacy, Athens, GA 30602
}

2Emory University School of Medicine/Veterans Affairs Medical Center, Decatur, GA 30033

\begin{abstract}
Various D- and L-thietanose nucleosides (22-27, 33-35, 50-52, 58-60) were synthesized from ${ }_{D}-$ and L-xylose. The four-membered thietane ring was efficiently synthesized by the cyclization of 1thioacetyl-3-mesylate (4/38) under basic conditions. Condensation with various heterocyclic bases was conducted via Pummerer-type rearrangement to afford various nucleoside derivatives. Among the synthesized nucleosides, o-uridine (23), D-cytidine (24), D-5-fluorocytidine (25) and L-cytidine (52) analogs showed moderate anti-HIV activity with $\mathrm{EC}_{50}$ of $6.9,1.3,5.8$ and $14.1 \mu \mathrm{M}$, respectively. However, these four nucleoside analogs are cytotoxic in PBM and CEM cells. The other nucleosides are neither active nor cytotoxic. Interestingly, the oxetanocin A analog 33 was not active. Comparison of the minimized RTs complexed with the corresponding triphosphates of the cytidine analog 24 and the adenosine analog $\mathbf{3 3}$ by molecular modeling studies showed that there is no difference in the binding mode of the triphosphate of the cytidine analog 24 to the active site of HIV-1 RT from that of the triphosphate of the adenosine analog 33. Modeling studies on the initial monophosphorylation step by deoxycytidine kinase showed that the catalytic efficiency of phosphorylation through a nucleophilic attack of the $4^{\prime}$-hydroxyl group of thietanose on the $\gamma$-phosphate of ATP is diminished in the case of ${ }_{\mathrm{L}}$-cytidine analog $(\mathbf{5 2})$ due to the increased distance between the $4^{\prime}$-hydroxyl group and the $\gamma$-phosphate.
\end{abstract}

\section{Introduction}

Nucleoside analogs have been well established as one of the richest source for antiviral agents despite of their toxicity ${ }^{1}$ and drug resistance. ${ }^{2}$ Various nucleosides have been reported as potent inhibitors against viruses such as human immunodeficiency virus (HIV) ${ }^{3}$ herpes simplex virus (HSV), ${ }^{4}$ hepatitis B virus (HBV) ${ }^{5}$ varicella zoster virus $(\mathrm{VZV})^{6}$ and human cytomegalovirus (HCMV). ${ }^{7}$ In the search for new antiviral nucleosides with favorable antiviral and toxicological profiles, numerous modifications have been conducted on naturally occurring nucleosides. A natural nucleoside, oxetanocin A, which has a four-membered oxetane ring instead of a five-membered ribose ring, showed antiviral and antitumor activity (Figure 1). ${ }^{8}$ The unique structure as well as the interesting biological activity of oxetanocin A have prompted nucleoside chemists to explore the antiviral and antitumor activities of the nucleosides with four-member ring sugar-like moieties. ${ }^{9}$ And the study of structure-activity relationships of oxetanocin A resulted in several bioactive analogs. ${ }^{9}$ Oxetanocin $\mathrm{T}$, in which the heterocyclic base is thymine, showed activity against VZV, HSV-1 and HSV-2, 10 oxetanocin $\mathrm{G}$ with guanine as the heterocyclic base, inhibited $\mathrm{HBV}$ replication in cell culture with an $\mathrm{EC}_{50}$ of $1.5 \mu \mathrm{M} .{ }^{11}$ The carbocyclic analog of oxetanocin $\mathrm{A}$ was also found to be active

Corresponding Author: Dr. C. K. Chu, Distinguished Research Professor, Department of Pharmaceutical and Biomedical Sciences, College of Pharmacy, The University of Georgia, Athens, GA 30602, USA, Tel : (706)-542-5379, Fax : (706)-542-5381, E-Mail : dchu@rx.uga.edu. 
against $\mathrm{HBV}$ and $\mathrm{HSV},{ }^{12}$ and the carbocyclic oxetanocin $\mathrm{G}$ was also active against $\mathrm{HBV}$ and HSV. ${ }^{12}$ Additionally thietanose nucleosides which have a four-membered thietane ring are of interest because the replacement of oxygen in the sugar ring with a sulfur usually increased the nucleoside's stability towards acidic hydrolysis as well as against phosphorylases which cleave the glycosyl bond, thus, resulting in the inactivation of nucleosides. ${ }^{13}$ However, only two synthetic methodologies for the synthesis of thietanose nucleosides have been reported in the literature, presumably due to the synthetic difficulties. ${ }^{14}$ Formulation of the thietane ring as well as the condensation reaction with heterocyclic bases occurred in poor to moderate yield, which was not sufficient enough to conduct the structure-activity relationship studies of thietanose nucleosides. For the synthesis of various thietanose nucleosides, an efficient method of synthesis of a common intermediate is required, from which various analogs can be prepared for the structure-activity relationships of the thietanose nucleosides. Herein, we report the synthesis and anti-HIV activity of various $\mathrm{D}^{-}$and $\mathrm{L}$-thietanose nucleosides including $\mathrm{D}_{\mathrm{D}}$ and $\mathrm{L}-\mathrm{3}^{\prime}-$ thio analogs of oxetanocin A.

\section{Results and discussion}

\section{Chemistry}

$\beta$-3-Hydroxy thietane such as compound 7 can serve as the key intermediate for the synthesis of various $2^{\prime}$-substituted thietanose nucleosides. The $\beta$-3-hydroxy group of $\mathbf{7}$ in the thietane ring can be derivatized to other desired moieties such as methylene $\mathbf{9}$, or hydroxymethyl group 10 etc. under mild reaction conditions. To synthesize the key intermediate compound $\mathbf{7}$, the substitution reaction of 1-thioacetyl-3-mesylate 4 , reported by several groups, ${ }^{15}$ was adapted with some modifications. To synthesize the ${ }_{\mathrm{D}}-3^{\prime}$-thio analogs with various heterocyclic bases (22-27, 33-35), D-xylose 1 was converted to the diol 2 in 5 steps by using the reported method (Scheme 1). ${ }^{16}$ The diol 2 was mesylated with $\mathrm{MsCl}$, TEA and DMAP to give the 1,3dimesylate 3 in $90 \%$ yield, which was selectively converted to the mono-thioacetate $\mathbf{4}$ by the treatment with KSAc in DMF at room temperature in $80 \%$ yield. By employing the similar substitution reaction as previously reported, 15 a solution of the mono-thioacetate $\mathbf{4}$ and $\mathrm{NaHCO}_{3}$ in deoxygenated $95 \%$ aqueous EtOH was refluxed under nitrogen atmosphere for 6 $\mathrm{h}$ to give compound $\mathbf{5}$ in $92 \%$ yield. The compound $\mathbf{5}$ was deprotected by the treatment with $4 \%$ TFA followed by neutralization with Amberlite ${ }^{\circledR}\left(\mathrm{OH}^{-}\right)$resin to give the triol 6 in $90 \%$ yield. The compound 6 was oxidatively cleaved to give the key intermediate 7 in $70 \%$ yield, from which a various 2 -substituted thietanose nucleosides were synthesized. For optimum yield of the 1,2-diol cleavage, several reaction conditions such as the amount of $\mathrm{NaIO}_{4}(1.2$ eq.), vigorous stirring, reaction time $(1 \mathrm{~h})$, and temperature $\left(0^{\circ} \mathrm{C}\right)$ turned out to be critical.

The selective protection of the primary alcohol in compound 7 with TBDPSCl was explored with a few base catalysts, from which 2,4,6-collidine was found to give the highest selectivity between the primary and secondary hydroxyl groups. Thus, treatment of $\mathbf{7}$ with triethylamine and a catalytic amount of 2,4,6-collidine in $\mathrm{CH}_{2} \mathrm{Cl}_{2}$ gave the mono-protected compound $\mathbf{8}$ in $85 \%$ yield with no di-protected compound. Compound $\mathbf{8}$ was then oxidized under Moffatt-type conditions using DMSO and acetic anhydride to give a ketone as the intermediate, which was converted to the methylene derivative with the Petasis' reagent $\left(\mathrm{Cp}_{2} \mathrm{TiMe}_{2}\right)$ to give compound 9 in $40 \%$ yield. Compound 9 underwent hydroboration by the treatment with $\mathrm{BH}_{3} \cdot \mathrm{SMe}_{2}$ followed by oxidation with $3 \% \mathrm{H}_{2} \mathrm{O}_{2}$ and $1 \mathrm{~N} \mathrm{NaOH}$ to give the undesired 2'- $\beta$-hydroxymethyl derivative $\mathbf{1 0}$ as the major product in $70 \%$ yield, along with the desired $2^{\prime}$ - $\alpha$-hydroxymethyl compound $\mathbf{1 1}$ in $12 \%$ yield. The sterically hindered nature of the $\beta$-side of compound $\mathbf{9}$ caused by the bulky silyl protecting group was probably unfavorable for the approach of $\mathrm{BH}_{3}$ from the $\beta$-side, resulting in the formation of the undesired $\beta$-configuration of the 2 '-hydroxymethyl group. This hypothesis can be supported by the similar result obtained for the synthesis of (-)cyclobut-A. ${ }^{17}$ In order to obtain the intermediate with the correct configuration at the 2 '- 
position, the major product $\mathbf{1 0}$ was oxidized to an aldehyde and equilibrated under basic conditions. Thus, Swern oxidation of compound $\mathbf{1 0}$ followed by epimerization with $\mathrm{NaOMe}$ and reduction with $\mathrm{NaBH}_{4}$ gave the desired product 11 in $47 \%$ overall yield in three steps. Compound $\mathbf{1 1}$ was protected by treating with TBDPSCl and imidazole to give compound $\mathbf{1 2}$ in $90 \%$ yield.

Condensation of the thietanose derivative $\mathbf{1 2}$ with heterocyclic bases was conducted by the Pummerer-type rearrangement after formation of a sulfoxide with mCPBA (Scheme 2). ${ }^{18}$ Silylated heterocyclic bases, such as thymine, uracil, 5-fluorouracil, 5-chlorouracil, 5bromouracil, 6-chlolopurine and 6-chloro-2-fluoropurine, were obtained under reflux conditions using HMDS and acetonitrile, which were condensed with the corresponding sulfoxide of $\mathbf{1 2}$ in the presence of TMSOTf, triethylamine and catalytic amount of $\mathrm{ZnI}_{2}$ to provide the protected nucleoside derivatives $(\mathbf{1 3}, \mathbf{1 4}, \mathbf{1 6}, \mathbf{1 7}, \mathbf{1 8}, 28$ and 29$)$ as $\alpha / \beta$ mixtures in $28-46 \%$ yield. For the pyrimidine nucleosides $\alpha$ and $\beta$ anomers cannot be separated from each other, while for the purine derivatives, it was possible to separate the desired $\beta$ anomers from their $\alpha$ anomers by using silica gel column chromatography. Condensation of compound $\mathbf{1 2}$ with thymine, uracil, 5-fluorouracil, 5-chlorouracil and 5-bromouracil gave anomeric mixtures of protected nucleosides 13, 14, 16, 17 and 18 with the $\beta / \alpha$ ratio of $2: 1$ in $46 \%, 40 \%, 37 \%$, $32 \%$ and $28 \%$ yield, respectively. The uracil, 5-fluorouracil, 5-chlorouracil and 5-bromouracil derivatives 14, 16, 17 and 18 were aminated by the treatment with 2,4,6triisopropylbenzenesulfonyl chloride, triethylamine and DMAP in acetonitrile followed by aqueous ammonia solution to give the cytosine, 5-fluorocytosine, 5-chlorocytosine and 5bromocytosine derivatives 15, 19, 20 and 21, respectively. The nucleoside analogs 13-15, 19-21 were treated with TBAF in THF at room temperature to afford pyrimidine thietanose nucleosides 22-27.

Compound 12 was condensed with 6-chloropurine and 6-chloro-2-fluoropurine to give compounds 28 and 29 as well as their $\alpha$-isomers in $40-45 \%$ yield with a $\beta / \alpha$ ratio of 5:4 (Scheme 2). Compound 28 was converted to the adenine derivative $\mathbf{3 0}$ in $72 \%$ yield by using $\mathrm{NaN}_{3}$ in DMF followed by hydrogenation with $10 \% \mathrm{Pd}(0)$ on carbon in methanol. Compound $\mathbf{2 8}$ was also converted to the inosine derivative $\mathbf{3 1}$ in $85 \%$ yield by treatment with $\mathrm{NaOMe}$ and 2mercaptoethanol in methanol. On the other hand, the guanosine analog 32 was obtained in 74 $\%$ yield by treatment of $\mathbf{2 9}$ with $\mathrm{NaOMe}$ and 2-mercaptoethanol in methanol followed by amination in ethanolic ammonia at $60^{\circ} \mathrm{C}$. Deprotection of compounds 30-32 by TBAF gave the purine thietanose nucleosides $\mathbf{3 3 - 3 5}$ in $89-94 \%$ yield.

The $\mathrm{L}-3^{\prime}$-thio analogs of oxetanocin A were also synthesized under similar reaction conditions starting from the opposite enantiomer, L-xylose (Scheme 3). L-Xylose was converted to the key intermediate 46, the enantiomer of compound 12, which was obtained through the thietane diol 41, the enantiomer of compound 7. After coupling of $\mathbf{4 6}$ with the appropriate silylated pyrimidine and purine bases, the $\mathrm{L}_{\mathrm{L}} 3^{\prime}$-thio analogs $(\mathbf{5 0 - 5 2 , 5 8 - 6 0})$ of oxetanocin A were obtained by using the same procedures employed for the synthesis of ${ }_{\mathrm{D}}$-isomers (Scheme 4).

\section{Anti-HIV activity}

The antiviral activity of the synthesized $\mathrm{D}^{-}$and L-thietanose nucleosides (22-27, 33-35, 50-52, 58-60) was evaluated against HIV-1 in human PBM cells in vitro using AZT as a positive control and the results are summarized in Table 1. Among the synthesized nucleosides, Duridine (23), D-cytidine (24), D-5-fluorocytidine and ${ }_{\mathrm{L}}$-cytidine (52) analogs show moderate antiHIV activity with an $\mathrm{EC}_{50}$ value of $6.9,1.3,5.8$ and $14.1 \mu \mathrm{M}$, respectively. However, these four nucleoside analogs are also cytotoxic in PBM cells and CEM cells.

We synthesized $\mathrm{D}$-cytidine analog at the early stages of this project, when some antiviral activity for $\mathrm{D}$-cytidine analog (24, Table 1) is observed, then we decided to explore the SAR at the 5- 
position of the pyrimidine ring. The addition of halogen atom at the 5-position of the pyrimidine ring has been found to alter the kinetic parameters as well as antiviral potency of the corresponding nucleoside analogues. ${ }^{19}$ It is well known that the modification of 5-position of the cytosine ring with fluorine may result in reduced toxicity and in some cases increase the antiviral potency. ${ }^{20}$ However, introduction of different halogens at the 5-position in this thietanose series $(\mathbf{2 5}, \mathbf{2 6} \& \mathbf{2 7})$, resulted in the decrease in antiviral potency (Table 1). The complete inactivity of $\mathbf{2 6}$ was unexpected. The other nucleosides showed neither anti-HIV activity nor cytotoxicity up to $100 \mu \mathrm{M}$. It is well known that nucleosides/nucleotides analogs can inhibit human DNA polymerases which may cause side effects such as cytotoxicity, mitochondrial toxicity, etc. ${ }^{21}$ Consequently, if compounds 24,2527 and 52 can be phosphorylated to triphosphates, the low selectivity of these nucleotides between the HIV RT and cellular polymerase may explain the observed antiviral activity as well as the cytotoxicity. Viral inhibition may also be due to the deleterious effect of the nucleosides on the cellular viability, caused by their metabolites to other cellular machineries other than polymerase (e.g. ribonucleotide reductase, CTP synthase etc. ${ }^{22}$ ). To confirm the hypothesis, however, more detail experiments have to be conducted. As all the purine analogs including the 3 '-thiooxetanocin A analog $\mathbf{3 3}$ showed no detectable anti-HIV activity while the compound $\mathbf{3 3}$ was found to have similar binding characteristics with the HIV-RT by molecular modeling studies (vide infra), the purine thietanose nucleosides might have a low level of phosphorylation by the initial nucleoside kinase, which probably results in a low, or if any, levels of the triphosphate.

\section{Molecular modeling studies}

The molecular modeling studies of the synthesized thietanose adenosine derivative $\mathbf{3 3}$ as well as oxetanocin A were conducted to compare the conformations of these two nucleosides with that of thymidine triphosphate in the crystal structure of HIV-1 reverse transcriptase (RT) (PDB code 1RTD). ${ }^{23}$ The most stable conformation of thietanose adenosine derivative $\mathbf{3 3}$ was obtained by a Monte Carlo conformational search using the molecular graphics and simulation program, MacroModel version 7.0 (Schrödinger, Inc.) ${ }^{24}$ The crystal structure of oxetanocin A was obtained from the Cambridge Structural Database. The three conformations of thietanose adenosine derivative 33, oxetanocin A and TTP were superimposed using Sybyl 6.7 (Figure 2). The $\mathrm{C} 3$ '-C4'bond (in blue) in thietanose adenosine derivative $\mathbf{3 3}$ is displaced by 0.6 $\AA$ from that of the $\mathrm{C}^{\prime}$ '-C5'bond (in orange) in TTP, and the $3^{\prime}$-sulfur atom in thietanose adenosine derivative 33 extrudes from that of the $3^{\prime}$-oxygen in oxetanocin A and the $4^{\prime}$-oxygen in TTP. Another noticeable feature is that $2^{\prime}$-hydroxymethyl groups of thietanose adenosine derivative $\mathbf{3 3}$ and oxetanocin A are completely overlapped with the $3^{\prime}$-hydroxy group of TTP. It is well known that the 3'-hydroxy pocket, composed of Asp113, Ala114, Tyr115 and Gln151, strengthens the binding of natural substrates to the active site of HIV-1 RT through hydrogen bonding, particularly with Tyr $115 .^{21}$ This $3^{\prime}$-hydroxy pocket also plays an important role in binding of AZTTP to HIV RT, which was demonstrated in our previous molecular modeling studies. ${ }^{25}$ Thus, the $2^{\prime}$-hydroxymethyl groups of thietanose adenosine derivative $\mathbf{3 3}$ could be nicely accommodated at the $3^{\prime}-\mathrm{OH}$ pocket, which would favorably contribute to their binding affinity to RT.

While the ${ }_{\mathrm{D}}$-cytidine analog $\mathbf{2 4}$ is moderately active against HIV, which has the same sugar conformation as D-adenosine analog $\mathbf{3 3}$ based on the Monte Carlo conformational search, the D-adenosine analog $\mathbf{3 3}$ does not show any anti-HIV activity. To understand the difference of anti-HIV activity between the cytidine analog 24 and adenosine analog 33 , molecular modeling studies using the crystal structure of HIV-1 RT (PDB code 1RTD) were conducted replacing TTP with the corresponding triphosphates of the nucleoside analogs 24 and $33 .{ }^{23}$ Each triphosphate was docked to the active site of HIV-1 RT and the resulting complex was minimized using Kollman-All Atom force field. In the minimized structures, both nucleoside 
triphosphates are nicely accommodated to the active site of HIV-1 RT without any steric hindrance with amino acid residues of the active site of RT. As expected, each hydroxy moiety of 2'-hydoxymethyl group $\left(-\mathrm{CH}_{2} \mathrm{OH}\right)$ of the two thietanose nucleoside triphosphates is hydrogen-bonded to Tyr 115 of $3^{\prime}$-hydroxy pocket in the active site of HIV RT as well as their own $\beta$-phosphate (Figure 3). From the molecular modeling studies, it is suggested that there would be no difference in the ability of both the nucleosides triphosphates to bind to the active site of HIV RT. Thus, the lack of anti-HIV activity of the adenosine analog $\mathbf{3 3}$ might have originated from the lack of phosphorylation by the initial kinase.

To investigate this possibility, we conducted molecular modeling studies of $\mathrm{D}$ - and $\mathrm{L}$-thietanose cytidine analog $(\mathbf{2 4 , 5 2})$ with deoxycytidine kinase (dCK, PDB code $1 \mathrm{P} 60) .{ }^{26}$ Detailed analysis of the reported crystal structure (1P60.pdb) revealed that Glu53 and Arg128 are the acid-base pair which abstracts the proton and initiates the catalysis (Figure 4). ${ }^{26}$ The distance between the nucleoside $5^{\prime}-\mathrm{OH}$ and Glu53 is critical for the phosphorylation. The $3^{\prime}-\mathrm{OH}$ is critical for activity, thus if $3-\mathrm{OH}$ is missing, then the catalytic efficiency decreases. ${ }^{27}$ The final minimized structures of the $\mathbf{2 4}$ and $\mathbf{5 2}$ revealed that there is considerable preference for $\mathrm{D}$-thietanose analog (24) over $\mathrm{L}$-thietanose analog (52). Catalytic efficiency of phosphorylation through a nucleophilic attack of the 4'-hydroxyl group of thietanose on the $\gamma$-phosphate of ATP is diminished in the case of compound (52) due to the increased distance between the 4'-hydroxyl group and the $\gamma$-phosphate. Slight steric clashes are also observed between Leu82 and the 2'hydroxymethyl group of $\mathbf{5 2}$ (Figure 5), which is due to the distinct binding mode of $\mathrm{L}$-thietanose analogs. Thus, it can be concluded from the studies that the increased distance for nucleophilic attack on the $\gamma$-phosphate coupled with the steric clashes observed for compound $\mathbf{5 2}$, makes it less likely to get phosphorylated as efficiently as compound $\mathbf{2 4}$, which may partially explain the lower anti-HIV activity.

In summary, various thietanose nucleosides such as $\mathrm{D}-$ and $\mathrm{L}-3^{\prime}$-thio analogs of oxetanocin A and $2^{\prime}-\alpha$ - and 2 '- $\beta$-hydroxythietanose nucleosides were efficiently synthesized from $\mathrm{D}-$ and $_{\mathrm{L}}-$ xylose. Among the synthesized nucleosides, o-uridine (23), p-cytidine (24), 5-fluorocytidine (25) and L-cytidine (52) analogs show moderate anti-HIV activity as well as cytotoxicity.

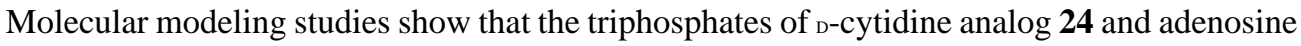
analog $\mathbf{3 3}$ are nicely accommodated to the active site of HIV RT through hydrogen bonding interactions, but the initial kinase (dCK) may not efficiently phosphorylate the compound $\mathbf{3 3}$, resulting in low level of its triphosphate, which, in turn, provides no anti-HIV activities.

\section{Experimental section}

Melting points were determined on a Mel-temp II apparatus and are uncorrected. Nuclear magnetic resonance spectra were recorded on a Varian Inova 500 spectrometer at $500 \mathrm{MHz}$ for ${ }^{1} \mathrm{H}$ NMR. Chemical shifts ( $\delta$ ) are reported as s (singlet), d (doublet), t (triplet), q (quartet), quin. (quintet), $\mathrm{m}$ (multiplet), or br s (broad singlet). UV spectra were recorded on a Beckman DU-650 spectrophotometer. Optical rotations were measured on a Jasco DIP-370 digital polarimeter. Mass spectra were recorded on a Micromass Autospec high-resolution mass spectrometer. TLC was performed on Uniplates (silica gel) purchased from Analtech Co. Column chromatography was performed using either silica gel-60 (220-440 mesh) for flash chromatography or silica gel G (TLC grade, $>440$ mesh) for vacuum flash column chromatography. Elemental analyses were performed by Atlantic Microlab Inc., Norcross, GA.

\section{1,2-O-Isopropylidene-3,5-di-O-mesyl- $\alpha$-o-ribofuranoside (3)}

A solution of compound $2(33.2 \mathrm{~g}, 175 \mathrm{mmol})$ and pyridine $(56.6 \mathrm{~mL}, 700 \mathrm{mmol})$ in $\mathrm{CH}_{2} \mathrm{Cl}_{2}$ $(500 \mathrm{~mL})$ was treated with $\mathrm{MsCl}(33.8 \mathrm{~mL}, 437 \mathrm{mmol})$ and DMAP $(4.3 \mathrm{~g}, 35 \mathrm{mmol})$ at $0^{\circ} \mathrm{C}$ for $18 \mathrm{~h}$. The reaction mixture was diluted with $\mathrm{CH}_{2} \mathrm{Cl}_{2}(500 \mathrm{~mL})$, washed with $1 \mathrm{~N} \mathrm{HCl}$, aq $\mathrm{NaHCO}_{3}$, and brine, and dried over $\mathrm{MgSO}_{4}$. The filtrate was concentrated and crystallized 
with a 1:10 mixture of $\mathrm{CH}_{2} \mathrm{Cl}_{2}$ and hexanes to give the product $\mathbf{3}(29.3 \mathrm{~g}, 0.0816 \mathrm{~mol}, 90 \%)$ as a white solid: mp $115 \sim 116^{\circ} \mathrm{C} ;[\alpha]^{22_{\mathrm{D}}} 77.8^{\circ}\left(\mathrm{c} 0.43, \mathrm{CHCl}_{3}\right) ;{ }^{1} \mathrm{H} \mathrm{NMR}\left(\mathrm{CDCl}_{3}\right) \delta 5.84(\mathrm{~d}, J=$ $3.4 \mathrm{~Hz}, 1 \mathrm{H}), 4.82 \sim 4.74(\mathrm{~m}, 2 \mathrm{H}), 4.55(\mathrm{dd}, J=11.8,1.9 \mathrm{~Hz}, 1 \mathrm{H}), 4.41 \sim 4.30(\mathrm{~m}, 2 \mathrm{H}), 3.16(\mathrm{~s}$, $3 \mathrm{H}), 3.08(\mathrm{~s}, 3 \mathrm{H}), 1.58(\mathrm{~s}, 3 \mathrm{H}), 1.38(\mathrm{~s}, 3 \mathrm{H})$; Anal. $\left(\mathrm{C}_{10} \mathrm{H}_{18} \mathrm{O}_{9} \mathrm{~S}_{2}\right) \mathrm{C}, \mathrm{H}$.

\section{5-S-Acetyl-1,2-O-isopropylidene-3-O-mesyl- $\alpha$-o-ribofuranoside (4)}

A solution of compound $3(81.5 \mathrm{~g}, 235 \mathrm{~mol})$ in DMF ( $400 \mathrm{~mL}$ ) was treated with $\mathrm{KSAc}(29.5 \mathrm{~g}$, $258 \mathrm{mmol}$ ) at room temperature. After $16 \mathrm{~h}$, the reaction mixture was diluted with EtOAc, washed with water $(2 \mathrm{X} 1 \mathrm{~L})$, and dried over $\mathrm{MgSO}_{4}$. The filtrate was concentrated and purified with $20 \%$ EtOAc in hexanes by silica gel column chromatography to give product $4(61.4 \mathrm{~g}$, $188 \mathrm{mmol}, 80 \%)$ as a brownish solid: $\mathrm{mp} 112 \sim 113^{\circ} \mathrm{C} ;[\alpha]^{23}{ }_{\mathrm{D}} 68.5^{\circ}\left(\mathrm{c} 0.35, \mathrm{CHCl}_{3}\right) ;{ }^{1} \mathrm{H} \mathrm{NMR}$ $\left(\mathrm{CDCl}_{3}\right) \delta 5.77(\mathrm{~d}, J=3.7 \mathrm{~Hz}, 1 \mathrm{H}), 4.75(\mathrm{t}, J=4.2 \mathrm{~Hz}, 1 \mathrm{H}), 4.48(\mathrm{dd}, J=8.8,4.6 \mathrm{~Hz}, 1 \mathrm{H})$, $4.31 \sim 4.25(\mathrm{~m}, 1 \mathrm{H}), 3.35(\mathrm{dd}, J=14.5,4.1 \mathrm{~Hz}, 1 \mathrm{H}), 3.23(J=14.5,5.1 \mathrm{~Hz}, 1 \mathrm{H}), 3.16(\mathrm{~s}, 3 \mathrm{H})$, $2.36(\mathrm{~s}, 3 \mathrm{H}), 1.55$ (s, 3H), 1.34 (s, 3H); Anal. $\left(\mathrm{C}_{11} \mathrm{H}_{18} \mathrm{O}_{7} \mathrm{~S}_{2}\right) \mathrm{C}, \mathrm{H}, \mathrm{S}$.

\section{3,5-Thioanhydro-1,2-O-isopropylidene- $\alpha$-o-xylofuranoside (5)}

A mixture of EtOH $(100 \mathrm{~mL})$ and water $(5 \mathrm{~mL})$ was refluxed under Ar for $2 \mathrm{~h}$ and cooled. Compound $4(2.12 \mathrm{~g}, 6.50 \mathrm{mmol})$ and solid $\mathrm{NaHCO}_{3}(1.09 \mathrm{~g}, 13.0 \mathrm{mmol})$ was added to the solvent and the resulting mixture was refluxed for $8 \mathrm{~h}$. The reaction mixture was cooled, diluted with $\mathrm{Et}_{2} \mathrm{O}$, filtered, and purified with $5 \% \mathrm{Et}_{2} \mathrm{O}$ in hexanes by silica gel column chromatography to give the product $5(1.12 \mathrm{~g}, 5.98 \mathrm{mmol}, 92 \%)$ as oil: $[\alpha]^{22}{ }_{\mathrm{D}} 78.7^{\circ}\left(\mathrm{c} 2.1, \mathrm{CHCl}_{3}\right) ;{ }^{1} \mathrm{H} \mathrm{NMR}$ $\left(\mathrm{CDCl}_{3}\right) \delta 6.41(\mathrm{~d}, J=3.4 \mathrm{~Hz}, 1 \mathrm{H}), 5.26(\mathrm{t}, J=5.3 \mathrm{~Hz}, 1 \mathrm{H}), 4.71(\mathrm{~d}, J=3.4 \mathrm{~Hz}, 1 \mathrm{H}), 4.08(\mathrm{~d}$, $J=5.3 \mathrm{~Hz}, 1 \mathrm{H}), 3.49(\mathrm{dd}, J=10.6,5.4 \mathrm{~Hz}, 1 \mathrm{H}), 2.84(\mathrm{~d}, J=10.6 \mathrm{~Hz}, 1 \mathrm{H}), 1.43(\mathrm{~s}, 3 \mathrm{H}), 1.36$ (s, 3H); Anal. $\left(\mathrm{C}_{8} \mathrm{H}_{12} \mathrm{O}_{3} \mathrm{~S}\right) \mathrm{C}, \mathrm{H}, \mathrm{S}$.

\section{3,5-Thioanhydro- $\alpha-\mathrm{-}-\mathrm{xylofuranose}(6)$}

Compound $5(1.10 \mathrm{~g}, 5.84 \mathrm{mmol})$ was with $4 \%$ TFA solution in water at room temperature for $8 \mathrm{~h}$, the reaction mixture was neutralized with Amberlite $(\mathrm{OH})$ resin which was pre-washed with water $(2 \mathrm{X} 100 \mathrm{~mL})$. After filtration, the filtrate was concentrated and purified with $50 \%$ EtOAc in hexanes by silica gel column chromatography to give the product $6(0.75 \mathrm{~g}, 5.06$ mmol, 87\%): ${ }^{1} \mathrm{H}$ NMR $\left(\mathrm{CDCl}_{3}\right)$ for major $\delta 6.11(\mathrm{~d}, J=2.3 \mathrm{~Hz}, 1 \mathrm{H}), 5.16 \sim 5.12(\mathrm{~m}, 1 \mathrm{H}), 4.17$ $(\mathrm{d}, J=2.5 \mathrm{~Hz}, 1 \mathrm{H}), 3.95(\mathrm{~d}, J=5.9 \mathrm{~Hz}, 1 \mathrm{H}), 3.50(\mathrm{dd}, J=10.9,6.3 \mathrm{~Hz}, 1 \mathrm{H}), 3.00(\mathrm{~d}, J=10.9$ $\mathrm{Hz}, 1 \mathrm{H})$, for minor $\delta 5.56(\mathrm{~s}, 1 \mathrm{H}), 5.29 \sim 5.24(\mathrm{~m}, 1 \mathrm{H}), 4.37(\mathrm{~s}, 1 \mathrm{H}), 3.95(\mathrm{~d}, J=5.9 \mathrm{~Hz}, 1 \mathrm{H})$, $3.64(\mathrm{dd}, J=10.9,6.1 \mathrm{~Hz}, 1 \mathrm{H}), 3.12(\mathrm{~d}, J=10.9 \mathrm{~Hz}, 1 \mathrm{H})$; Anal. $\left(\mathrm{C}_{5} \mathrm{H}_{8} \mathrm{O}_{3} \mathrm{~S}\right) \mathrm{C}, \mathrm{H}, \mathrm{S}$.

\section{(2R,3S)-2-Hydroxymethyl-thietan-3-ol (7)}

A solution of compound $6(1.92 \mathrm{~g}, 12.9 \mathrm{mmol})$ in $\mathrm{MeOH}(50 \mathrm{~mL})$ was treated with an aqueous solution of $\mathrm{NaIO}_{4}(3.04 \mathrm{~g}, 14.2 \mathrm{mmol})$ in water $(25 \mathrm{~mL})$ drop wise at $0^{\circ} \mathrm{C}$ for $10 \mathrm{~min}$ with vigorous stirring. After $20 \mathrm{~min}$, well-grounded $\mathrm{NaBH}_{4}$ was added portion wise to the reaction mixture at $0^{\circ} \mathrm{C}$. After $30 \mathrm{~min}$, the resulting mixture was filtered and the filtrate was neutralized with $1 \mathrm{~N} \mathrm{HCl}$ and concentrated. The residue was dissolved in a mixture of $\mathrm{CH}_{2} \mathrm{Cl}_{2}$ and $\mathrm{MeOH}$ (1:1) and the white solid was filtered off. The filtrate was concentrated and purified with $3 \sim 5 \% \mathrm{MeOH}$ in $\mathrm{CH}_{2} \mathrm{Cl}_{2}$ by silica gel column chromatography to give the products 7 (1.08g, $9.0 \mathrm{mmol}, 70 \%):[\alpha]^{24}{ }_{\mathrm{D}} 166.2^{\circ}(\mathrm{c} 0.63, \mathrm{MeOH}) ;{ }^{1} \mathrm{H} \mathrm{NMR}\left(\mathrm{CDCl}_{3}\right) \delta 5.00$ (quin. $J=8.1 \mathrm{~Hz}$, $1 \mathrm{H}), 4.09 \sim 3.98(\mathrm{~m}, 2 \mathrm{H}), 3.85(\mathrm{~d}, J=8.9 \mathrm{~Hz}, 1 \mathrm{H}), 3.76 \sim 3.71(\mathrm{~m}, 1 \mathrm{H}), 3.37 \sim 3.24(\mathrm{~m}, 3 \mathrm{H})$; Anal. $\left(\mathrm{C}_{4} \mathrm{H}_{8} \mathrm{O}_{2} \mathrm{~S} .0 .35 \mathrm{H}_{2} \mathrm{O}\right) \mathrm{C}, \mathrm{H}, \mathrm{S}$.

\section{(2R,3S)-2-(tert-Butyl-diphenyl-silanyloxymethyl)-thietan-3-ol (8)}

A solution of compound $7(5.00 \mathrm{~g}, 41.6 \mathrm{mmol})$, triethylamine $(11.6 \mathrm{~mL}, 83.2 \mathrm{mmol})$, and 2,4,6collidine $(0.46 \mathrm{~mL}, 4.2 \mathrm{mmol})$ in $\mathrm{CH}_{2} \mathrm{Cl}_{2}$ was treated with TBDPSCl $(11.45 \mathrm{~mL}, 43.7 \mathrm{mmol})$ at $0^{\circ} \mathrm{C}$ for $2 \mathrm{~h}$. The resulting mixture was concentrated and purified with $5 \%$ EtOAc in hexanes 
by silica gel column chromatography to give the product $8(11.9 \mathrm{~g}, 33.2 \mathrm{mmol}, 82 \%)$ as oil: $[\alpha]^{20}{ }_{\mathrm{D}} 74.1^{\circ}\left(\mathrm{c} 0.91, \mathrm{CHCl}_{3}\right) ;{ }^{1} \mathrm{H} \mathrm{NMR}\left(\mathrm{CDCl}_{3}\right) \delta 7.84 \sim 7.38(\mathrm{~m}, 10 \mathrm{H}), 5.06$ (quin, $J=8.1 \mathrm{~Hz}$, $1 \mathrm{H}), 4.19 \sim 4.10(\mathrm{~m}, 2 \mathrm{H}), 3.88(\mathrm{~d}, J=9.7 \mathrm{~Hz}, 1 \mathrm{H}), 3.73 \sim 3.67(\mathrm{~m}, 1 \mathrm{H}), 3.54(\mathrm{t}, J=8.3 \mathrm{~Hz}, 1 \mathrm{H})$, 3.33 (t, $J=8.3 \mathrm{~Hz}, 1 \mathrm{H}), 1.12$ (s, 9H); Anal. $\left(\mathrm{C}_{20} \mathrm{H}_{26} \mathrm{O}_{2} \mathrm{SSi}\right) \mathrm{C}, \mathrm{H}, \mathrm{S}$.

tert-Butyl-[(2S)-3-methylene-thietan-2-ylmethoxy]-diphenylsilane (9)

Compound $8(10.9 \mathrm{~g}, 30.4 \mathrm{mmol})$ was treated with DMSO $(45 \mathrm{~mL})$ and $\mathrm{Ac}_{2} \mathrm{O}(30 \mathrm{~mL})$ at room temperature for overnight. The reaction mixture was quenched with ice, diluted with $\mathrm{Et}_{2} \mathrm{O}$ (500 $\mathrm{mL}$ ), washed with water. The organic layer was dried over anhydrous $\mathrm{Na}_{2} \mathrm{SO}_{4}$, and concentrated. The residue was purified with $3 \%$ EtOAc in hexanes by silica gel column chromatography to give the intermediate ketone $(10.0 \mathrm{~g}, 28.1 \mathrm{mmol}, 92 \%)$ as oil. A mixture of titanocene dichloride $(38.7 \mathrm{~g}, 115 \mathrm{mmol})$ in $\mathrm{Et}_{2} \mathrm{O}(1 \mathrm{~L})$ was treated with $1.6 \mathrm{M} \mathrm{MeLi}$ solution $(214 \mathrm{~mL})$ in $\mathrm{Et}_{2} \mathrm{O}$ at room temperature for $2 \mathrm{~h}$. The reaction mixture was quenched with ice and extracted with $\mathrm{Et}_{2} \mathrm{O}$. The organic layer was dried over anhydrous $\mathrm{Na}_{2} \mathrm{SO}_{4}$ and concentrated to dryness. This reagent (Petasis reagent) was dissolved in THF $(80 \mathrm{~mL})$. A solution of the intermediate ketone $(10.0 \mathrm{~g}, 28.1 \mathrm{mmol})$ in $\mathrm{Et}_{2} \mathrm{O}(50 \mathrm{~mL})$ was treated with the freshly prepared Petasis reagent solution. The resulting mixture was refluxed at $60^{\circ} \mathrm{C}$ bath temperature. After $48 \mathrm{~h}$, the reaction mixture was cooled to room temperature, diluted with hexanes, and filtered through the silica gel pad. The filtrate was concentrated and purified with $2 \%$ EtOAc in hexanes by silica gel column chromatography to give the product $9(4.12 \mathrm{~g}, 11.6 \mathrm{mmol}, 41 \%)$ as oil: $[\alpha]^{22}{ }_{\mathrm{D}} 73.6^{\circ}\left(\mathrm{c} 0.80, \mathrm{CH}_{2} \mathrm{Cl}_{2}\right) ;{ }^{1} \mathrm{H} \mathrm{NMR}\left(\mathrm{CDCl}_{3}\right) \delta 7.72 \sim 7.65(\mathrm{~m}, 4 \mathrm{H}), 7.47 \sim 7.37(\mathrm{~m}, 6 \mathrm{H})$, $4.86(\mathrm{~d}, J=2.1 \mathrm{~Hz}, 1 \mathrm{H}), 4.71(\mathrm{~d}, J=2.1 \mathrm{~Hz}, 1 \mathrm{H}), 4.44 \sim 4.37(\mathrm{~m}, 1 \mathrm{H}), 4.00(\mathrm{dd}, J=10.3,6.8$ $\mathrm{Hz}, 1 \mathrm{H}), 3.87$ (dd, $J=10.3,6.8 \mathrm{~Hz}, 1 \mathrm{H}), 3.84 \sim 3.74(\mathrm{~m}, 2 \mathrm{H}), 1.06$ (s, 9H); Anal. $\left(\mathrm{C}_{21} \mathrm{H}_{26} \mathrm{OSSi}\right)$ $\mathrm{C}, \mathrm{H}, \mathrm{S}$.

[(2S,3R)-2-(tert-Butyl-diphenyl-silanyloxymethyl)-thietan-3-yl]-methanol (10)

A solution of compound $9(4.12 \mathrm{~g}, 11.6 \mathrm{mmol})$ in THF $(200 \mathrm{~mL})$ was treated with $2 \mathrm{M}$ $\mathrm{BH}_{3} \mathrm{SMe}_{2}$ solution $(11.5 \mathrm{~mL})$ in THF at $0^{\circ} \mathrm{C}$ for $30 \mathrm{~min}$. The reaction mixture was warmed up to room temperature and stirred for $2 \mathrm{~h}$. The reaction mixture was quenched with $3 \% \mathrm{H}_{2} \mathrm{O}_{2}$ $(26 \mathrm{~mL})$ and $1 \mathrm{~N} \mathrm{NaOH}(23 \mathrm{~mL})$. After $2 \mathrm{~h}$, the reaction mixture was treated with sat. $\mathrm{Na}_{2} \mathrm{~S}_{2} \mathrm{O}_{3}$, and extracted with EtOAc. The organic layer was washed with brine and dried over $\mathrm{Na}_{2} \mathrm{SO}_{4}$. The filtrate was concentrated and purified with $10 \%$ EtOAc in hexanes by silica gel column chromatography to give the product $10(3.35 \mathrm{~g}, 8.13 \mathrm{mmol}, 70 \%$ yield $)$ as well as compound $11\left(0.51 \mathrm{~g}, 1.37 \mathrm{mmol}, 12 \%\right.$ yield): $[\alpha]^{22}{ }_{\mathrm{D}} 43.4^{\circ}\left(\mathrm{c} 1.18, \mathrm{CHCl}_{3}\right) ;{ }^{1} \mathrm{H} \mathrm{NMR}$ $\left(\mathrm{CDCl}_{3}\right) \delta 7.78 \sim 7.32(\mathrm{~m}, 10 \mathrm{H}), 4.28(\mathrm{t}, J=10.1 \mathrm{~Hz}, 1 \mathrm{H}), 4.01(\mathrm{t}, J=9.9 \mathrm{~Hz}, 1 \mathrm{H}), 3.80 \sim 3.42$ (m, 5H), 3.02 2.83 (m, 2H), 1.07 (s, 9H); Anal. $\left(\mathrm{C}_{21} \mathrm{H}_{28} \mathrm{O}_{2} \mathrm{SSi}\right) \mathrm{C}, \mathrm{H}, \mathrm{S}$.

\section{[(2R,3S)-2-(tert-Butyl-diphenyl-silanyloxymethyl)-thietan-3-yl]-methanol (11)}

Oxalyl chloride $(1.56 \mathrm{~mL}, 17.9 \mathrm{mmol})$ was added drop wise to a solution of DMSO $(1.90 \mathrm{~mL}$, $26.8 \mathrm{mmol})$ in $\mathrm{CH}_{2} \mathrm{Cl}_{2}(30 \mathrm{~mL})$ at $-78^{\circ} \mathrm{C}$. After $10 \mathrm{~min}$, a solution of compound $\mathbf{1 0}(3.33 \mathrm{~g}$, $8.94 \mathrm{mmol})$ in $\mathrm{CH}_{2} \mathrm{Cl}_{2}(20 \mathrm{~mL})$ was added to the reaction mixture at $-78^{\circ} \mathrm{C}$. After $20 \mathrm{~min}$, TEA $\left(5.0 \mathrm{~mL}, 36 \mathrm{mmol}\right.$ ) was added at $-78^{\circ} \mathrm{C}$. After $10 \mathrm{~min}$, the reaction mixture was warmed up to room temperature for $1 \mathrm{~h}$. The resulting mixture was diluted with $\mathrm{CH}_{2} \mathrm{Cl}_{2}$, and washed with water. The organic layer was dried over anhydrous $\mathrm{Na}_{2} \mathrm{SO}_{4}$ and concentrated to dryness. The aldehyde was dissolved in $\mathrm{MeOH}(30 \mathrm{~mL})$, and treated with $\mathrm{NaOMe}(1.45 \mathrm{~g}, 26.8 \mathrm{mmol})$ for $16 \mathrm{~h}$. The resulting mixture was treated with $\mathrm{NaBH}_{4}(1.01 \mathrm{~g}, 26.7 \mathrm{mmol})$ for $2 \mathrm{~h}$. The reaction mixture was neutralized with $1 \mathrm{~N} \mathrm{HCl}$, concentrated to a tenth volume of the solution, extracted with $\mathrm{CH}_{2} \mathrm{Cl}_{2}$. The organic layer was dried over anhydrous $\mathrm{Na}_{2} \mathrm{SO}_{4}$, concentrated, filtered and purified by silica get column chromatography with $10 \%$ EtOAc in hexanes to give the product 11 (1.58g, $4.24 \mathrm{mmol}, 47 \%$ yield): $[\alpha]^{24}{ }_{\mathrm{D}} 40.7^{\circ}\left(\mathrm{c} 0.81, \mathrm{CH}_{2} \mathrm{Cl}_{2}\right) ;{ }^{1} \mathrm{H} \mathrm{NMR}\left(\mathrm{CDCl}_{3}\right) \delta$ 
7.70 7.36 (m, 10H), 3.82 3.58 (m, 5H), 3.22 3.10 (m, 1H), 3.01 2.93 (m, 2H), $1.06(\mathrm{~s}, 9 \mathrm{H})$; Anal. $\left(\mathrm{C}_{21} \mathrm{H}_{28} \mathrm{O}_{2} \mathrm{SSi}\right) \mathrm{C}, \mathrm{H}, \mathrm{S}$.

\section{(2R,3S)-2,3-Bis-(tert-butyl-diphenyl-silanyloxymethyl)-thietane (12)}

A solution of compound $11(2.00 \mathrm{~g}, 5.37 \mathrm{mmol})$ and imidazole $(0.77 \mathrm{~g}, 11 \mathrm{mmol})$ in $\mathrm{CH}_{2} \mathrm{Cl}_{2}$ was treated with TBDPSCl $(1.54 \mathrm{~mL}, 5.92 \mathrm{mmol})$ at room temperature for $3 \mathrm{~h}$. The reaction mixture was concentrated and purified with $2 \%$ EtOAc in hexanes to give the product $12(2.95 \mathrm{~g}$, $4.83 \mathrm{mmol}, 90 \%)$ as oil: $[\alpha]^{22}{ }_{\mathrm{D}} 45.0^{\circ}\left(\mathrm{c} 0.38, \mathrm{CH}_{2} \mathrm{Cl}_{2}\right) ;{ }^{1} \mathrm{H} \mathrm{NMR}\left(\mathrm{CDCl}_{3}\right) \delta 7.70 \sim 7.33(\mathrm{~m}$, $20 \mathrm{H}), 3.90(\mathrm{dd}, J=9.7,6.1 \mathrm{~Hz}, 1 \mathrm{H}), 3.77(\mathrm{dd}, J=10.2,6.6 \mathrm{~Hz}, 1 \mathrm{H}), 3.73 \sim 3.65(\mathrm{~m}, 3 \mathrm{H})$, 3.16 2.95 (m, 3H), $1.05(\mathrm{~s}, 9 \mathrm{H}), 1.04(\mathrm{~s}, 9 \mathrm{H})$; Anal. $\left(\mathrm{C}_{37} \mathrm{H}_{46} \mathrm{O}_{2} \mathrm{SSi}_{2}\right) \mathrm{C}, \mathrm{H}, \mathrm{S}$.

\section{1-[(2R,3S,4R/S)-2,3-Bis-(tert-butyl-diphenyl-silanyloxymethyl)-thietan-4-yl]-thymine (13)}

A solution of compound $12(0.250 \mathrm{~g}, 0.409 \mathrm{mmol})$ in $\mathrm{CH}_{2} \mathrm{Cl}_{2}$ was treated with a solution of $77 \%$ mCPBA $(0.092 \mathrm{~g}, 0.411 \mathrm{mmol})$ in $\mathrm{CH}_{2} \mathrm{Cl}_{2}$ drop wise at $-78^{\circ} \mathrm{C}$. The mixture was stirred at $-78^{\circ} \mathrm{C}$ for $30 \mathrm{~min}$. The reaction was quenched with aq. $\mathrm{Na}_{2} \mathrm{~S}_{2} \mathrm{O}_{3}$, diluted with $\mathrm{CH}_{2} \mathrm{Cl}_{2}$, washed with aq $\mathrm{Na}_{2} \mathrm{~S}_{2} \mathrm{O}_{3}$, aq $\mathrm{NaHCO}_{3}$, and brine, and dried over $\mathrm{MgSO}_{4}$. The filtrate was concentrated to dryness. The crude sulfoxide was used for the next reaction without further purification. A mixture of thymine $(0.155 \mathrm{~g}, 1.23 \mathrm{mmol})$ in acetonitrile $(10 \mathrm{~mL})$ and HMDS $(10 \mathrm{~mL})$ was refluxed for $3 \mathrm{~h}$ until the solution became clear. After evaporation, the residue was treated successively with a solution of the crude sulfoxide in toluene $(10 \mathrm{~mL})$, triethylamine $(0.11 \mathrm{~mL}$, $0.79 \mathrm{mmol})$, TMSOTf $(0.16 \mathrm{~mL}, 0.88 \mathrm{mmol})$, and $\mathrm{ZnI}_{2}(0.039 \mathrm{~g}, 0.12 \mathrm{mmol})$ at $0^{\circ} \mathrm{C}$. After 24 $\mathrm{h}$, the reaction was quenched with water at $0^{\circ} \mathrm{C}$ and the reaction mixture was diluted with $\mathrm{CH}_{2} \mathrm{Cl}_{2}$. The organic layer was dried over $\mathrm{NaSO}_{4}$, filtered, concentrated and purified with $30 \%$ EtOAc in hexane by preparative TLC to give the product $13(0.138 \mathrm{~g}, 0.188 \mathrm{mmol}, 46 \%)$ as an $\alpha / \beta$ mixture (1:3): $\mathrm{UV}\left(\mathrm{CH}_{2} \mathrm{Cl}_{2}\right) \lambda_{\max } 270.0 \mathrm{~nm} ;{ }^{1} \mathrm{H} \mathrm{NMR}\left(\mathrm{CDCl}_{3}\right) \delta 9.03,8.99(2 \mathrm{br} \mathrm{s}, 1 \mathrm{H})$, $7.98,7.80(2 \mathrm{~s}, 1 \mathrm{H}), 7.72 \sim 7.30(\mathrm{~m}, 20 \mathrm{H}), 6.30(\mathrm{~d}, J=6.8 \mathrm{~Hz}, 0.75 \mathrm{H}), 6.20(\mathrm{~d}, J=7.7 \mathrm{~Hz}$, $0.25 \mathrm{H}), 3.88$ (dd, $J=9.8,5.9 \mathrm{~Hz}, 0.25 \mathrm{H}), 3.81 \sim 3.45(\mathrm{~m}, 5 \mathrm{H}), 3.26 \sim 3.19(\mathrm{~m}, 0.75 \mathrm{H}), 1.87$, $1.83(2 \mathrm{~s}, 3 \mathrm{H}), 1.07,1.044,1.036,0.98(4 \mathrm{~s}, 18 \mathrm{H})$; Anal. $\left(\mathrm{C}_{42} \mathrm{H}_{50} \mathrm{~N}_{2} \mathrm{O}_{4} \mathrm{SSi}_{2}\right) \mathrm{C}, \mathrm{H}, \mathrm{N}, \mathrm{S}$.

\section{1-[(2R,3S,4R/S)-2,3-Bis-(tert-butyl-diphenyl-silanyloxymethyl)-thietan-4-yl]-uracil (14)}

See the procedure of compound $\mathbf{1 3}$ for condensation reaction with thymine. The title compound 14 was obtained on 0.301 -mmol scale in $40 \%$ yield: $\mathrm{UV}\left(\mathrm{CH}_{2} \mathrm{Cl}_{2}\right) \lambda_{\max } 265.0 \mathrm{~nm} ;{ }^{1} \mathrm{H}$ NMR $\left(\mathrm{CDCl}_{3}\right) \delta 8.58,8.53(2 \mathrm{br} \mathrm{s}, 1 \mathrm{H}), 8.19(\mathrm{~d}, J=7.8 \mathrm{~Hz}, 0.3 \mathrm{H}), 8.16(\mathrm{~d}, J=7.8 \mathrm{~Hz}, 0.7 \mathrm{H})$, $7.70 \sim 7.33(\mathrm{~m}, 20 \mathrm{H}), 6.24(\mathrm{~d}, J=6.8 \mathrm{~Hz}, 0.7 \mathrm{H}), 6.20(\mathrm{~d}, J=7.8 \mathrm{~Hz}, 0.3 \mathrm{H}), 5.69(\mathrm{~d}, J=8.8 \mathrm{~Hz}$, $0.3 \mathrm{H}), 5.60(\mathrm{~d}, J=7.8 \mathrm{~Hz}, 0.7 \mathrm{H}), 3.85(\mathrm{dd}, J=10.7,5.8 \mathrm{~Hz}, 0.3 \mathrm{H}), 3.77 \sim 3.46(\mathrm{~m}, 5 \mathrm{H})$, 3.26 3.20 (m, 0.7H), 1.07, 1.05, 1.03, $0.98(4 \mathrm{~s}, 18 \mathrm{H})$; Anal. $\left(\mathrm{C}_{41} \mathrm{H}_{48} \mathrm{~N}_{2} \mathrm{O}_{4} \mathrm{SSi}_{2}\right) \mathrm{C}, \mathrm{H}, \mathrm{N}, \mathrm{S}$.

\section{1-[(2R,3S,4R/S)-2,3-Bis-(tert-butyl-diphenyl-silanyloxymethyl)-thietan-4-yl]-cytosine (15)}

A solution of compound $14(0.120 \mathrm{~g}, 0.166 \mathrm{mmol})$ in acetonitrile was treated with triethylamine (0.07 mL, $0.50 \mathrm{mmol}), 2,4,6$-triisopropylbenzenesulfonyl chloride $(0.151 \mathrm{~g}, 0.499 \mathrm{mmol})$, and DMAP $(0.061 \mathrm{~g}, 0.50 \mathrm{mmol})$ at room temperature. After $16 \mathrm{~h}$, ammonia water was added to the resulting mixture. After $3 \mathrm{~h}$, the mixture was diluted with $\mathrm{CH}_{2} \mathrm{Cl}_{2}(50 \mathrm{~mL})$, and the organic layer was washed with brine, dried over $\mathrm{Na}_{2} \mathrm{SO}_{4}$, concentrated and purified by column chromatography with $5 \% \mathrm{MeOH}$ in $\mathrm{CH}_{2} \mathrm{Cl}_{2}$ to give a $\alpha / \beta$ mixture of compound $\mathbf{1 5}(0.090 \mathrm{~g}$, $0.125 \mathrm{mmol}, 75 \%$ yield): $\mathrm{UV}\left(\mathrm{CH}_{2} \mathrm{Cl}_{2}\right) \lambda_{\max } 285.5 \mathrm{~nm} ;{ }^{1} \mathrm{H} \mathrm{NMR}\left(\mathrm{CDCl}_{3}\right) \delta 8.31(\mathrm{~d}, J=7.8$ $\mathrm{Hz}, 0.3 \mathrm{H}), 8.25(\mathrm{~d}, J=7.8 \mathrm{~Hz}, 0.7 \mathrm{H}), 7.69 \sim 7.28(\mathrm{~m}, 20 \mathrm{H}), 6.26(\mathrm{~d}, J=6.8 \mathrm{~Hz}, 0.7 \mathrm{H}), 6.24(\mathrm{~d}$, $J=7.8 \mathrm{~Hz}, 0.3 \mathrm{H}), 5.62(\mathrm{~d}, J=6.8 \mathrm{~Hz}, 0.3 \mathrm{H}), 5.58(\mathrm{~d}, J=6.8 \mathrm{~Hz}, 0.7 \mathrm{H}), 3.92(\mathrm{dd}, J=10.7,5.8$ $\mathrm{Hz}, 0.3 \mathrm{H}$ ), 3.83 3.46 (m, 5H), 3.18 3.11 (m, 0.7H), 1.07, 1.03, 1.00, (3s, 18H); Anal. $\left(\mathrm{C}_{41} \mathrm{H}_{49} \mathrm{~N}_{3} \mathrm{O}_{3} \mathrm{SSi}_{2}\right) \mathrm{C}, \mathrm{H}, \mathrm{N}, \mathrm{S}$. 
1-[(2R,3S,4R/S)-2,3-Bis-(tert-butyl-diphenyl-silanyloxymethyl)-thietan-4-yl]-5-fluorouracil (16)

See the procedure of compound $\mathbf{1 3}$ for condensation reaction with thymine. The title compound 16 was obtained on 0.389 -mmol scale in $37 \%$ yield: $\mathrm{UV}\left(\mathrm{CH}_{2} \mathrm{Cl}_{2}\right) \lambda_{\max } 271 \mathrm{~nm} ;{ }^{1} \mathrm{H} \mathrm{NMR}$ $\left(\mathrm{CDCl}_{3}\right) \delta 8.58,8.53(2 \mathrm{br} \mathrm{s}, 1 \mathrm{H}), 8.19(\mathrm{~d}, J=7.8 \mathrm{~Hz}, 0.3 \mathrm{H}), 8.16(\mathrm{~d}, J=7.8 \mathrm{~Hz}, 0.7 \mathrm{H})$, $7.70 \sim 7.33(\mathrm{~m}, 20 \mathrm{H}), 6.24(\mathrm{~d}, J=6.8 \mathrm{~Hz}, 0.7 \mathrm{H}), 6.20(\mathrm{~d}, J=7.8 \mathrm{~Hz}, 0.3 \mathrm{H}), 5.69(\mathrm{~d}, J=8.8 \mathrm{~Hz}$, $0.3 \mathrm{H}), 5.60(\mathrm{~d}, J=7.8 \mathrm{~Hz}, 0.7 \mathrm{H}), 3.85(\mathrm{dd}, J=10.7,5.8 \mathrm{~Hz}, 0.3 \mathrm{H}), 3.77 \sim 3.46(\mathrm{~m}, 5 \mathrm{H})$, 3.26 3.20 (m, 0.7H), 1.07, 1.05, 1.03, $0.98(4 \mathrm{~s}, 18 \mathrm{H})$; HRMS (ESI, M+Na ${ }^{+}$) Calcd for $\mathrm{C}_{41} \mathrm{H}_{47} \mathrm{FN}_{2} \mathrm{O}_{4} \mathrm{SSi}_{2} \mathrm{Na} 761.2677$, found 761.2671.

1-[(2R,3S,4R/S)-2,3-Bis-(tert-butyl-diphenyl-silanyloxymethyl)-thietan-4-yl]-5-chlorouracil (17)

See the procedure of compound $\mathbf{1 3}$ for condensation reaction with thymine. The title compound 17 was obtained on $0.291-\mathrm{mmol}$ scale in $32 \%$ yield: $\mathrm{UV}\left(\mathrm{CH}_{2} \mathrm{Cl}_{2}\right) \lambda_{\max } 273.0 \mathrm{~nm} ;{ }^{1} \mathrm{H} \mathrm{NMR}$ $\left(\mathrm{CDCl}_{3}\right) \delta 8.58,8.53(2 \mathrm{br} \mathrm{s}, 1 \mathrm{H}), 8.19(\mathrm{~d}, J=7.8 \mathrm{~Hz}, 0.3 \mathrm{H}), 8.16(\mathrm{~d}, J=7.8 \mathrm{~Hz}, 0.7 \mathrm{H})$, $7.70 \sim 7.33(\mathrm{~m}, 20 \mathrm{H}), 6.24(\mathrm{~d}, J=6.8 \mathrm{~Hz}, 0.7 \mathrm{H}), 6.20(\mathrm{~d}, J=7.8 \mathrm{~Hz}, 0.3 \mathrm{H}), 5.69(\mathrm{~d}, J=8.8 \mathrm{~Hz}$, $0.3 \mathrm{H}), 5.60(\mathrm{~d}, J=7.8 \mathrm{~Hz}, 0.7 \mathrm{H}), 3.85(\mathrm{dd}, J=10.7,5.8 \mathrm{~Hz}, 0.3 \mathrm{H}), 3.77 \sim 3.46(\mathrm{~m}, 5 \mathrm{H})$, $3.26 \sim 3.20(\mathrm{~m}, 0.7 \mathrm{H}), 1.07,1.05,1.03,0.98(4 \mathrm{~s}, 18 \mathrm{H})$; HRMS (ESI, M+Na ${ }^{+}$) Calcd for $\mathrm{C}_{41} \mathrm{H}_{47} \mathrm{ClN}_{2} \mathrm{O}_{4} \mathrm{SSi}_{2} \mathrm{Na}$ 777.2382, found 777.2378.

1-[(2R,3S,4R/S)-2,3-Bis-(tert-butyl-diphenyl-silanyloxymethyl)-thietan-4-yl]-5-bromouracil (18)

See the procedure of compound $\mathbf{1 3}$ for condensation reaction with thymine. The title compound 18 was obtained on $0.375-\mathrm{mmol}$ scale in $28 \%$ yield: $\mathrm{UV}\left(\mathrm{CH}_{2} \mathrm{Cl}_{2}\right) \lambda_{\max } 278.0 \mathrm{~nm} ;{ }^{1} \mathrm{H} \mathrm{NMR}$ $\left(\mathrm{CDCl}_{3}\right) \delta 8.58,8.53(2 \mathrm{br} \mathrm{s}, 1 \mathrm{H}), 8.19(\mathrm{~d}, J=7.8 \mathrm{~Hz}, 0.3 \mathrm{H}), 8.16(\mathrm{~d}, J=7.8 \mathrm{~Hz}, 0.7 \mathrm{H})$, $7.70 \sim 7.33(\mathrm{~m}, 20 \mathrm{H}), 6.24(\mathrm{~d}, J=6.8 \mathrm{~Hz}, 0.7 \mathrm{H}), 6.20(\mathrm{~d}, J=7.8 \mathrm{~Hz}, 0.3 \mathrm{H}), 5.69(\mathrm{~d}, J=8.8 \mathrm{~Hz}$, $0.3 \mathrm{H}), 5.60(\mathrm{~d}, J=7.8 \mathrm{~Hz}, 0.7 \mathrm{H}), 3.85(\mathrm{dd}, J=10.7,5.8 \mathrm{~Hz}, 0.3 \mathrm{H}), 3.77 \sim 3.46(\mathrm{~m}, 5 \mathrm{H})$, $3.26 \sim 3.20(\mathrm{~m}, 0.7 \mathrm{H}), 1.07,1.05,1.03,0.98(4 \mathrm{~s}, 18 \mathrm{H})$; HRMS (ESI, Mona ${ }^{+}$) Clad for $\mathrm{C}_{41} \mathrm{H}_{47} \mathrm{BrN}_{2} \mathrm{O}_{4} \mathrm{SSi}_{2} \mathrm{Na}$ 821.1876, found 821.1867.

1-[(2R,3S,4R/S)-2,3-Bis-(tert-butyl-diphenyl-silanyloxymethyl)-thietan-4-yl]-5-fluorocytosine (19)

See the procedure of compound $\mathbf{1 4}$ for the amination reaction with uridine analog. The title compound 19 was obtained on 0.284 -mmol scale in $73 \%$ yield: $\mathrm{UV}\left(\mathrm{CH}_{2} \mathrm{Cl}_{2}\right) \lambda_{\max } 285$ $\mathrm{nm} ;{ }^{1} \mathrm{H} \mathrm{NMR}\left(\mathrm{CDCl}_{3}\right) \delta 8.31(\mathrm{~d}, J=7.8 \mathrm{~Hz}, 0.3 \mathrm{H}), 8.25(\mathrm{~d}, J=7.8 \mathrm{~Hz}, 0.7 \mathrm{H}), 7.69 \sim 7.28(\mathrm{~m}$, $20 \mathrm{H}), 6.26(\mathrm{~d}, J=6.8 \mathrm{~Hz}, 0.7 \mathrm{H}), 6.24(\mathrm{~d}, J=7.8 \mathrm{~Hz}, 0.3 \mathrm{H}), 5.62(\mathrm{~d}, J=6.8 \mathrm{~Hz}, 0.3 \mathrm{H}), 5.58$ (d, $J=6.8 \mathrm{~Hz}, 0.7 \mathrm{H}), 3.92(\mathrm{dd}, J=10.7,5.8 \mathrm{~Hz}, 0.3 \mathrm{H}), 3.83 \sim 3.46(\mathrm{~m}, 5 \mathrm{H}), 3.18 \sim 3.11(\mathrm{~m}$, $0.7 \mathrm{H}), 1.07,1.03,1.00,(3 \mathrm{~s}, 18 \mathrm{H})$; HRMS (ESI, $\mathrm{M}+\mathrm{Na}^{+}$) Calcd for $\mathrm{C}_{41} \mathrm{H}_{48} \mathrm{FN}_{3} \mathrm{O}_{3} \mathrm{SSi}_{2} \mathrm{Na}$ 760.2837 , found 760.2845 .

1-[(2R,3S,4R/S)-2,3-Bis-(tert-butyl-diphenyl-silanyloxymethyl)-thietan-4-yl]-5chlorocytosine (20)

See the procedure of compound $\mathbf{1 4}$ for the amination reaction with uridine analog. The title compound 20 was obtained on 0.318 -mmol scale in $68 \%$ yield: $\mathrm{UV}\left(\mathrm{CH}_{2} \mathrm{Cl}_{2}\right) \lambda_{\max } 277$ $\mathrm{nm} ;{ }^{1} \mathrm{H}$ NMR $\left(\mathrm{CDCl}_{3}\right) \delta 8.31(\mathrm{~d}, J=7.8 \mathrm{~Hz}, 0.3 \mathrm{H}), 8.25(\mathrm{~d}, J=7.8 \mathrm{~Hz}, 0.7 \mathrm{H}), 7.69 \sim 7.28(\mathrm{~m}$, $20 \mathrm{H}), 6.26(\mathrm{~d}, J=6.8 \mathrm{~Hz}, 0.7 \mathrm{H}), 6.24(\mathrm{~d}, J=7.8 \mathrm{~Hz}, 0.3 \mathrm{H}), 5.62(\mathrm{~d}, J=6.8 \mathrm{~Hz}, 0.3 \mathrm{H}), 5.58$ $(\mathrm{d}, J=6.8 \mathrm{~Hz}, 0.7 \mathrm{H}), 3.92(\mathrm{dd}, J=10.7,5.8 \mathrm{~Hz}, 0.3 \mathrm{H}), 3.83 \sim 3.46(\mathrm{~m}, 5 \mathrm{H}), 3.18 \sim 3.11(\mathrm{~m}$, 0.7H), 1.07, 1.03, 1.00, (3s, 18H); HRMS (ESI, M+Na+) Calcd for $\mathrm{C}_{41} \mathrm{H}_{48} \mathrm{FN}_{3} \mathrm{O}_{3} \mathrm{SSi}_{2} \mathrm{Na}$ 776.2541 , found 776.2533 . 


\section{1-[(2R,3S,4R/S)-2,3-Bis-(tert-butyl-diphenyl-silanyloxymethyl)-thietan-4-yl]-5- bromocytosine (21)}

See the procedure of compound $\mathbf{1 4}$ for the amination reaction with uridine analog. The title compound 21 was obtained on 0.338 -mmol scale in $63 \%$ yield: $\mathrm{UV}\left(\mathrm{CH}_{2} \mathrm{Cl}_{2}\right) \lambda_{\max } 292$ $\mathrm{nm} ;{ }^{1} \mathrm{H}$ NMR $\left(\mathrm{CDCl}_{3}\right) \delta 8.31(\mathrm{~d}, J=7.8 \mathrm{~Hz}, 0.3 \mathrm{H}), 8.25(\mathrm{~d}, J=7.8 \mathrm{~Hz}, 0.7 \mathrm{H}), 7.69 \sim 7.28(\mathrm{~m}$, $20 \mathrm{H}), 6.26(\mathrm{~d}, J=6.8 \mathrm{~Hz}, 0.7 \mathrm{H}), 6.24(\mathrm{~d}, J=7.8 \mathrm{~Hz}, 0.3 \mathrm{H}), 5.62(\mathrm{~d}, J=6.8 \mathrm{~Hz}, 0.3 \mathrm{H}), 5.58$ (d, $J=6.8 \mathrm{~Hz}, 0.7 \mathrm{H}), 3.92(\mathrm{dd}, J=10.7,5.8 \mathrm{~Hz}, 0.3 \mathrm{H}), 3.83 \sim 3.46(\mathrm{~m}, 5 \mathrm{H}), 3.18 \sim 3.11(\mathrm{~m}$, $0.7 \mathrm{H}), 1.07,1.03,1.00,(3 \mathrm{~s}, 18 \mathrm{H})$; HRMS (ESI, $\mathrm{M}+\mathrm{Na}^{+}$) Calcd for $\mathrm{C}_{41} \mathrm{H}_{48} \mathrm{BrN}_{3} \mathrm{O}_{3} \mathrm{SSi}_{2} \mathrm{Na}$ 820.2036 , found 820.2027 .

\section{1-[(2R,3S,4R)-2,3-dihydroxymethyl-thietan-4-yl]-thymine (22)}

A solution of compound $\mathbf{1 3}(0.130 \mathrm{~g}, 0.177 \mathrm{mmol})$ in THF $(10 \mathrm{~mL})$ was treated with $0.35 \mathrm{~mL}$ of $1 \mathrm{M}$ TBAF solution in acetonitrile at $0^{\circ} \mathrm{C}$. After $3 \mathrm{~h}$, the reaction mixture was concentrated and purified by prep TLC with $7 \% \mathrm{MeOH}$ in $\mathrm{CH}_{2} \mathrm{Cl}_{2}$ to give compound $22(0.029 \mathrm{~g}, 0,112$ mmol, $63 \%$ yield) and $\alpha$-isomer $\left(0.011 \mathrm{~g}, 0.043 \mathrm{mmol}, 24 \%\right.$ yield): $\mathrm{mp}>200^{\circ} \mathrm{C}(\mathrm{dec}.) ;[\alpha]^{26_{\mathrm{D}}}$ $-86.8^{\circ}$ (c 0.075, DMSO); UV ( $\left.\mathrm{H}_{2} \mathrm{O}\right) \lambda_{\max } 264.0 \mathrm{~nm}(\varepsilon 9,400, \mathrm{pH} 2) .262 .0 \mathrm{~nm}(\varepsilon 9,900, \mathrm{pH} 7)$, $265.5 \mathrm{~nm}(\varepsilon 7,100, \mathrm{pH} 11) ;{ }^{1} \mathrm{H}$ NMR $(\mathrm{MeOH}) \delta 8.30(\mathrm{~s}, 1 \mathrm{H}), 6.08(\mathrm{~d}, J=6.8 \mathrm{~Hz}, 1 \mathrm{H}), 3.76$ $(\mathrm{dd}, J=11.7,3.9 \mathrm{~Hz}, 1 \mathrm{H}), 3.72(\mathrm{dd}, J=11.7,4.9 \mathrm{~Hz}, 1 \mathrm{H}), 3.58(\mathrm{~d}, J=3.9 \mathrm{~Hz}, 2 \mathrm{H}), 3.54 \sim 3.49$ $(\mathrm{m}, 1 \mathrm{H}), 3.32 \sim 3.26(\mathrm{~m}, 1 \mathrm{H}), 1.95(\mathrm{~s}, 3 \mathrm{H})$; Anal. $\left(\mathrm{C}_{10} \mathrm{H}_{14} \mathrm{~N}_{2} \mathrm{O}_{4} \mathrm{~S}\right) \mathrm{C}, \mathrm{H}, \mathrm{N}, \mathrm{S}$.

\section{1-[(2R,3S,4R)-2,3-dihydroxymethyl-thietan-4-yl]-uracil (23)}

See the procedure of compound $\mathbf{2 2}$ for deprotection reaction with $1 \mathrm{M}$ TBAF solution. The title compound 23 was obtained on 0.083 -mmol scale in $59 \%$ yield: $\mathrm{mp}>200^{\circ} \mathrm{C}\left(\mathrm{dec}\right.$.); $[\alpha]^{22} \mathrm{D}-35.4$ ${ }^{\circ}(\mathrm{c} 0.17, \mathrm{MeOH}) ; \mathrm{UV}\left(\mathrm{H}_{2} \mathrm{O}\right) \lambda_{\max } 265.5 \mathrm{~nm}(\varepsilon 9,200, \mathrm{pH} 2), 265.5 \mathrm{~nm}(\varepsilon$ 8,500, pH 7), 265.5 $\mathrm{nm}(\varepsilon 6,900, \mathrm{pH} 11) ;{ }^{1} \mathrm{H}$ NMR $(\mathrm{MeOH}) \delta 8.46(\mathrm{~d}, \mathrm{~J}=7.8 \mathrm{~Hz}, 1 \mathrm{H}), 6.07(\mathrm{~d}, \mathrm{~J}=6.8 \mathrm{~Hz}, 1 \mathrm{H})$, $5.81(\mathrm{~d}, \mathrm{~J}=7.8 \mathrm{~Hz}, 1 \mathrm{H}), 3.76(\mathrm{dd}, \mathrm{J}=\mathrm{Hz}, 1 \mathrm{H}), 3.71(\mathrm{dd}, \mathrm{J}=\mathrm{Hz}, 1 \mathrm{H}), 3.60(\mathrm{~d}, \mathrm{~J}=\mathrm{Hz}, 2 \mathrm{H})$, 3.54 3.49 (m, 1H), 3.28 3.21 (m, 1H); Anal. $\left(\mathrm{C}_{9} \mathrm{H}_{12} \mathrm{~N}_{2} \mathrm{O}_{4} \mathrm{~S}\right) \mathrm{C}, \mathrm{H}, \mathrm{N}, \mathrm{S}$.

\section{1-[(2R,3S,4R)-2,3-dihydroxymethyl-thietan-4-yl]-cytosine (24)}

See the procedure of compound $\mathbf{2 2}$ for deprotection reaction with $1 \mathrm{M}$ TBAF solution. The title compound 24 was obtained on 0.118 -mmol scale in $59 \%$ yield: $\mathrm{mp} 125 \sim 126^{\circ} \mathrm{C}$; $[\alpha]^{23}{ }_{\mathrm{D}}-59.2$ ${ }^{\circ}(\mathrm{c} 0.14, \mathrm{MeOH}) ; \mathrm{UV}\left(\mathrm{H}_{2} \mathrm{O}\right) \lambda_{\max } 282.5 \mathrm{~nm}(\varepsilon 12,500, \mathrm{pH} 2), 274.5 \mathrm{~nm}(\varepsilon$ 9,700, pH 7), 275.5 $\mathrm{nm}(\varepsilon 9,600, \mathrm{pH} 11) ;{ }^{1} \mathrm{H}$ NMR $(\mathrm{MeOH}) \delta 8.43(\mathrm{~d}, J=6.8 \mathrm{~Hz}, 1 \mathrm{H}), 6.04(\mathrm{~s}, J=6.8 \mathrm{~Hz}, 1 \mathrm{H})$, $6.00(\mathrm{~d}, J=7.8 \mathrm{~Hz}, 1 \mathrm{H}), 3.75(\mathrm{dd}, J=11.7,4.9 \mathrm{~Hz}, 1 \mathrm{H}), 3.69(\mathrm{dd}, J=11.7,5.6 \mathrm{~Hz}, 1 \mathrm{H})$, $3.66 \sim 3.58(\mathrm{~m}, 1 \mathrm{H}), 3.51 \sim 3.47(\mathrm{~m}, 1 \mathrm{H}), 3.14$ (quin, $J=6.8 \mathrm{~Hz}, 1 \mathrm{H}$ ); Anal. $\left(\mathrm{C}_{9} \mathrm{H}_{12} \mathrm{~N}_{2} \mathrm{O}_{4} \mathrm{~S}\right) \mathrm{C}$, $\mathrm{H}, \mathrm{N}, \mathrm{S}$.

\section{1-[(2R,3S,4R)-2,3-dihydroxymethyl-thietan-4-yl]-5-fluorocytosine (25)}

See the procedure of compound $\mathbf{2 2}$ for deprotection reaction with $1 \mathrm{M}$ TBAF solution. The title compound 25 was obtained on 0.109 -mmol scale in $51 \%$ yield: $\mathrm{mp} 125 \sim 126^{\circ} \mathrm{C}$; $[\alpha]^{26}{ }_{\mathrm{D}}-53.3$ ○ (c 0.30, MeOH); UV ( $\left.\mathrm{H}_{2} \mathrm{O}\right) \lambda_{\max } 272 \mathrm{~nm}(\varepsilon$ 9,226, pH 2), $288 \mathrm{~nm}(\varepsilon 14,146, \mathrm{pH} 7), 278 \mathrm{~nm}$ $(\varepsilon 12,588, \mathrm{pH} 11) ;{ }^{1} \mathrm{H}$ NMR $(\mathrm{MeOH}) \delta 8.65(\mathrm{~d}, J=6.8 \mathrm{~Hz}, 1 \mathrm{H}), 6.04(\mathrm{dd}, J=6.6,2.2 \mathrm{~Hz}, 1 \mathrm{H})$, $3.76(\mathrm{dd}, J=9.0,4.4 \mathrm{~Hz}, 2 \mathrm{H}), 3.67(\mathrm{dd}, J=5.6,3.9 \mathrm{~Hz}, 2 \mathrm{H}), 3.55 \sim 3.51(\mathrm{~m}, 1 \mathrm{H}), 3.24 \sim 3.20$ (m, $1 \mathrm{H})$; Anal. $\left(\mathrm{C}_{9} \mathrm{H}_{12} \mathrm{~N}_{2} \mathrm{O}_{4} \mathrm{~S}\right) \mathrm{C}, \mathrm{H}, \mathrm{N}, \mathrm{S}$.

\section{1-[(2R,3S,4R)-2,3-dihydroxymethyl-thietan-4-yl]-5-chlorocytosine (26)}

See the procedure of compound $\mathbf{2 2}$ for deprotection reaction with $1 \mathrm{M}$ TBAF solution. The title compound 26 was obtained on 0.112 -mmol scale in $46 \%$ yield: $\mathrm{mp} 125 \sim 126^{\circ} \mathrm{C}$; $[\alpha]^{25} \mathrm{D}-43.4$ ${ }^{\circ}(\mathrm{c} 0.22, \mathrm{MeOH}) ; \mathrm{UV}\left(\mathrm{H}_{2} \mathrm{O}\right) \lambda_{\max } 297 \mathrm{~nm}(\varepsilon$ 5,486, pH 2), $291 \mathrm{~nm}(\varepsilon$ 4,567, pH 7), $291 \mathrm{~nm}$ $\left(\varepsilon\right.$ 6,903, pH 11); ${ }^{1} \mathrm{H}$ NMR $(\mathrm{MeOH}) \delta 8.61(\mathrm{~s}, 1 \mathrm{H}), 5.87(\mathrm{~d}, J=6.3 \mathrm{~Hz}, 1 \mathrm{H}), 3.62(\mathrm{dd}, J=8.5$, 
$4.1 \mathrm{~Hz}, 2 \mathrm{H}), 3.55(\mathrm{dd}, J=5.6,2.9 \mathrm{~Hz}, 1 \mathrm{H}), 3.42 \sim 3.38(\mathrm{~m}, 1 \mathrm{H}), 3.13 \sim 3.07(\mathrm{~m}, 1 \mathrm{H})$; Anal. $\left(\mathrm{C}_{9} \mathrm{H}_{12} \mathrm{~N}_{2} \mathrm{O}_{4} \mathrm{~S}\right) \mathrm{C}, \mathrm{H}, \mathrm{N}, \mathrm{S}$.

\section{1-[(2R,3S,4R)-2,3-dihydroxymethyl-thietan-4-yl]-5-bromocytosine (27)}

See the procedure of compound $\mathbf{2 2}$ for deprotection reaction with $1 \mathrm{M}$ TBAF solution. The title compound 27 was obtained on 0.105 -mmol scale in $37 \%$ yield: $\mathrm{mp} 125 \sim 126^{\circ} \mathrm{C}$; $[\alpha]^{23}{ }_{\mathrm{D}}-25.3$ ${ }^{\circ}(\mathrm{c} 0.14, \mathrm{MeOH}) ; \mathrm{UV}\left(\mathrm{H}_{2} \mathrm{O}\right) \lambda_{\max } 302 \mathrm{~nm}(\varepsilon$ 8,311, pH 2), $293 \mathrm{~nm}(\varepsilon$ 6,585, pH 7), $293 \mathrm{~nm}$ $(\varepsilon 7,005, \mathrm{pH} 11) ;{ }^{1} \mathrm{H}$ NMR $(\mathrm{MeOH}) \delta 8.83(\mathrm{~s}, 1 \mathrm{H}), 6.00(\mathrm{~s}, J=6.4 \mathrm{~Hz}, 1 \mathrm{H}), 3.74(\mathrm{dd}, J=8.1$, $4.1 \mathrm{~Hz}, 2 \mathrm{H}), 3.68(\mathrm{dd}, J=5.6,3.2 \mathrm{~Hz}, 2 \mathrm{H}), 3.56 \sim 3.52(\mathrm{~m}, 1 \mathrm{H}), 3.33 \sim 3.28(\mathrm{~m}, 1 \mathrm{H})$; Anal. $\left(\mathrm{C}_{9} \mathrm{H}_{12} \mathrm{~N}_{2} \mathrm{O}_{4} \mathrm{~S}\right) \mathrm{C}, \mathrm{H}, \mathrm{N}, \mathrm{S}$.

\section{9-[(2R,3S,4R)-2,3-Bis-(tert-butyl-diphenyl-silanyloxymethyl)-thietan-4-yl]-6-chloropurine} (28)

See the procedure of compound $\mathbf{1 3}$ for condensation reaction with thymine. The title compound 28 as well as $\alpha$-isomer were obtained on 0.622 -mmol scale in $45 \%$ yield as a 5:4 mixture of compound 28 and $\alpha$-isomer: $[\alpha]^{23}{ }_{\mathrm{D}} 16.8^{\circ}\left(\mathrm{c} 0.65, \mathrm{CHCl}_{3}\right) ; \mathrm{UV}\left(\mathrm{CH}_{2} \mathrm{Cl}_{2}\right) \lambda_{\max } 264.5 \mathrm{~nm} ;{ }^{1} \mathrm{H}$ $\operatorname{NMR}\left(\mathrm{CDCl}_{3}\right) \delta 8.87(\mathrm{~s}, 1 \mathrm{H}), 8.86(\mathrm{~s}, 1 \mathrm{H}), 7.66 \sim 7.27(\mathrm{~m}, 20 \mathrm{H}), 6.56(\mathrm{~d}, J=7.1 \mathrm{~Hz}, 1 \mathrm{H})$, 3.82 3.62 (m, 5H), 3.39 3.31 (m, 1H), $1.06(\mathrm{~s}, 9 \mathrm{H}), 1.02$ (s, 9H); Anal. $\left(\mathrm{C}_{42} \mathrm{H}_{47} \mathrm{ClN}_{4} \mathrm{O}_{2} \mathrm{SSi}_{2}\right) \mathrm{C}, \mathrm{H}, \mathrm{N}, \mathrm{S}$.

\section{9-[(2R,3S,4R)-2,3-Bis-(tert-butyl-diphenyl-silanyloxymethyl)-thietan-4-yl]-6-chloro2- fluoropurine $(29)$}

See the procedure of compound $\mathbf{1 3}$ for condensation reaction with thymine. The title compound 29 as well as $\alpha$-isomer were obtained on $0.797-\mathrm{mmol}$ scale in $40 \%$ yield as a 5:4 mixture of compound 29 and $\alpha$-isomer: $[\alpha]^{24_{\mathrm{D}}} 9.3^{\circ}\left(\mathrm{c} 0.21, \mathrm{CHCl}_{3}\right) ; \mathrm{UV}\left(\mathrm{CH}_{2} \mathrm{Cl}_{2}\right) \lambda_{\max } 254.5 \mathrm{~nm} ;{ }^{1} \mathrm{H}$ NMR $\left(\mathrm{CDCl}_{3}\right) \delta 8.85(\mathrm{~s}, 1 \mathrm{H}), 7.64 \sim 7.24(\mathrm{~m}, 20 \mathrm{H}), 6.47(\mathrm{~d}, J=6.8 \mathrm{~Hz}, 1 \mathrm{H}), 3.83 \sim 3.65(\mathrm{~m}$, $5 \mathrm{H}), 3.36 \sim 3.28(\mathrm{~m}, 1 \mathrm{H}), 1.06(\mathrm{~s}, 9 \mathrm{H}), 1.03(\mathrm{~s}, 9 \mathrm{H})$; Anal. $\left(\mathrm{C}_{42} \mathrm{H}_{46} \mathrm{ClFN}_{4} \mathrm{O}_{2} \mathrm{SSi}_{2}\right) \mathrm{C}, \mathrm{H}, \mathrm{N}, \mathrm{S}$.

\section{9-[(2R,3S,4R)-2,3-Bis-(tert-butyl-diphenyl-silanyloxymethyl)-thietan-4-yl]-adenine (30)}

A solution of compound $28(0.202 \mathrm{~g}, 0.265 \mathrm{mmol})$ in DMF $(2 \mathrm{~mL})$ was treated with $\mathrm{NaN}_{3}$ $(0.172 \mathrm{~g}, 2.65 \mathrm{~mol})$ at room temperature for $16 \mathrm{~h}$. The resulting mixture was directly filtered through silica gel pad using eluent as a 1:1 mixture of hexanes and EtOAc. The filtrate was concentrated to dryness. A solution of the crude azide in $\mathrm{MeOH}(15 \mathrm{~mL})$ was treated with $0.030 \mathrm{~g}$ of $\mathrm{Pd}(0) / \mathrm{C}$ and $\mathrm{H}_{2}$ balloon for $48 \mathrm{~h}$. The resulting mixture was filtered through celite pad and the filtrate was concentrated and purified by column chromatography with $2 \% \mathrm{MeOH}$ in $\mathrm{CH}_{2} \mathrm{Cl}_{2}$ to give the product 30 (0.143g, $0.192 \mathrm{mmol}, 72 \%$ yield): $[\alpha]^{23} \mathrm{D} 41.5^{\circ}$ (c 0.17 , $\left.\mathrm{CH}_{2} \mathrm{Cl}_{2}\right) ; \mathrm{UV}\left(\mathrm{CH}_{2} \mathrm{Cl}_{2}\right) \lambda_{\max } 272.0 \mathrm{~nm} ;{ }^{1} \mathrm{H} \mathrm{NMR}\left(\mathrm{CDCl}_{3}\right) \delta 8.44(\mathrm{~s}, 1 \mathrm{H}), 7.85(\mathrm{~s}, 1 \mathrm{H})$, 7.66 7.30 (m, 20H), 6.06 (br s, $2 \mathrm{H}), 6.03(\mathrm{~d}, J=8.6 \mathrm{~Hz}, 1 \mathrm{H}) ; 3.91 \sim 3.83(\mathrm{~m}, 2 \mathrm{H}), 3.74 \sim 3.54$ (m, 3H), 3.43 3.34 (m, 1H), 1.09 (s, 9H), 1.05 (s, 9H); Anal. $\left(\mathrm{C}_{42} \mathrm{H}_{49} \mathrm{~N}_{5} \mathrm{O}_{2} \mathrm{SSi}_{2}\right) \mathrm{C}, \mathrm{H}, \mathrm{N}, \mathrm{S}$.

\section{9-[(2R,3S,4R)-2,3-Bis-(tert-butyl-diphenyl-silanyloxymethyl)-thietan-4-yl]-hypoxanthine (31)}

A solution of compound $28(0.134 \mathrm{~g}, 0.176 \mathrm{mmol}), 2$-mercaptoethanol $(0.049 \mathrm{~mL}, 0.70 \mathrm{mmol})$ and $\mathrm{NaOMe}(0.038 \mathrm{~g}, 0.70 \mathrm{mmol})$ in $\mathrm{MeOH}$ was refluxed for $6 \mathrm{~h}$. The mixture was cooled to room temperature, neutralized with $\mathrm{AcOH}$, concentrated, and purified by column chromatography with $2 \% \mathrm{MeOH}$ in $\mathrm{CH}_{2} \mathrm{Cl}_{2}$ to give the product $31(0.112 \mathrm{~g}, 0.150 \mathrm{mmol}, 85 \%$ yield): $[\alpha]^{24}{ }_{\mathrm{D}} 27.9^{\circ}\left(\mathrm{c} 0.21, \mathrm{CH}_{2} \mathrm{Cl}_{2}\right) ; \mathrm{UV}\left(\mathrm{CH}_{2} \mathrm{Cl}_{2}\right) \lambda_{\max } 262.5 \mathrm{~nm} ;{ }^{1} \mathrm{H} \mathrm{NMR}\left(\mathrm{CDCl}_{3}\right) \delta 8.45$ $(\mathrm{s}, 1 \mathrm{H}), 7.72(\mathrm{~s}, 1 \mathrm{H}), 7.68 \sim 7.12(\mathrm{~m}, 20 \mathrm{H}), 6.56(\mathrm{~d}, J=5.9 \mathrm{~Hz}, 1 \mathrm{H}), 3.89(\mathrm{dd} J=10.7,5.9 \mathrm{~Hz}$, $1 \mathrm{H}), 3.85 \sim 3.68$ (m, 4H), 3.39 3.32 (m, 1H), 1.05 (s, 9H), 1.01 (s, 9H); Anal. $\left(\mathrm{C}_{42} \mathrm{H}_{48} \mathrm{~N}_{4} \mathrm{O}_{3} \mathrm{SSi}_{2}\right) \mathrm{C}, \mathrm{H}, \mathrm{N}, \mathrm{S}$. 


\section{9-[(2R,3S,4R)-2,3-Bis-(tert-butyl-diphenyl-silanyloxymethyl)-thietan-4-yl]-guanine (32)}

A solution of compound $29(0.138 \mathrm{~g}, 0.177 \mathrm{mmol}), 2$-mercaptoethanol $(0.049 \mathrm{~mL}, 0.70 \mathrm{mmol})$ and $\mathrm{NaOMe}(0.019 \mathrm{~g}, 0.35 \mathrm{mmol})$ in $\mathrm{MeOH}$ was refluxed for $4 \mathrm{~h}$. The mixture was cooled to room temperature, neutralized with $\mathrm{AcOH}$, concentrated, and filtered through silica gel pad. The filtrate was concentrated to dryness. The residue was treated with ethanolic ammonia at $60^{\circ} \mathrm{C}$ for $6 \mathrm{~h}$. The reaction mixture was concentrated and purified by column chromatography with $2 \% \mathrm{MeOH}$ in $\mathrm{CH}_{2} \mathrm{Cl}_{2}$ to give the product $32(0.115 \mathrm{~g}, 0.151 \mathrm{mmol}, 74 \%$ yield $):[\alpha]^{24}{ }_{\mathrm{D}}$ $17.8^{\circ}\left(\mathrm{c} 0.12, \mathrm{CHCl}_{3}\right) ; \mathrm{UV}\left(\mathrm{CH}_{2} \mathrm{Cl}_{2}\right) \lambda_{\max } 264.0 \mathrm{~nm} ;{ }^{1} \mathrm{H} \mathrm{NMR}\left(\mathrm{CDCl}_{3}\right) \delta 8.36(\mathrm{~s}, 1 \mathrm{H})$, $7.75 \sim 7.24(\mathrm{~m}, 20 \mathrm{H}), 6.36(\mathrm{~d}, J=6.8 \mathrm{~Hz}, 1 \mathrm{H}), 3.95 \sim 3.63(\mathrm{~m}, 5 \mathrm{H}), 3.37 \sim 3.30(\mathrm{~m}, 1 \mathrm{H}), 1.04(\mathrm{~s}$, $9 \mathrm{H}), 0.99$ (s, 9H); Anal. $\left(\mathrm{C}_{42} \mathrm{H}_{49} \mathrm{~N}_{5} \mathrm{O}_{3} \mathrm{SSi}_{2}\right) \mathrm{C}, \mathrm{H}, \mathrm{N}, \mathrm{S}$.

\section{9-[(2R,3S,4R)-2,3-dihydroxymethyl-thietan-4-yl]-adenine (33)}

See the procedure of compound $\mathbf{2 2}$ for deprotection reaction with 1M TBAF solution. The title compound 33 was obtained on 0.188 -mmol scale in $94 \%$ yield: $\mathrm{mp}>200^{\circ} \mathrm{C} ;[\alpha]^{25} \mathrm{D} 95.2^{\circ}(\mathrm{c}$ 0.057, $\mathrm{MeOH}) ; \mathrm{UV}\left(\mathrm{H}_{2} \mathrm{O}\right) \lambda_{\max } 272.5 \mathrm{~nm}(\varepsilon 15,000, \mathrm{pH} 2) .270 .5 \mathrm{~nm}(\varepsilon 10,000, \mathrm{pH} 7), 271.5$ $\mathrm{nm}(\varepsilon 10,000, \mathrm{pH} 11) ;{ }^{1} \mathrm{H}$ NMR $(\mathrm{MeOH}) \delta 8.84(\mathrm{~s}, 1 \mathrm{H}), 8.24(\mathrm{~s}, 1 \mathrm{H}), 6.17(\mathrm{~d}, J=6.6 \mathrm{~Hz}, 1 \mathrm{H})$, $3.80(\mathrm{~d}, J=4.6 \mathrm{~Hz}, 2 \mathrm{H}), 3.73(\mathrm{dd}, J=11.7,6.6 \mathrm{~Hz}, 1 \mathrm{H}), 3.69(\mathrm{dd}, J=11.7,5.1 \mathrm{~Hz}, 1 \mathrm{H})$, 3.62 3.56 (m, 1H), 3.55 3.48 (m, 1H); Anal. $\left(\mathrm{C}_{10} \mathrm{H}_{13} \mathrm{~N}_{5} \mathrm{O}_{2} \mathrm{~S}\right) \mathrm{C}, \mathrm{H}, \mathrm{N}, \mathrm{S}$.

\section{9-[(2R,3S,4R)-2,3-dihydroxymethyl-thietan-4-yl]-hypoxanthine (34)}

See the procedure of compound $\mathbf{2 2}$ for deprotection reaction with $1 \mathrm{M}$ TBAF solution. The title compound 34 was obtained on 0.150 -mmol scale in $89 \%$ yield: $\mathrm{mp} 213 \sim 214^{\circ} \mathrm{C} ;[\alpha]^{26}{ }_{\mathrm{D}} 22.0^{\circ}$ (c 0.13, MeOH); UV( $\left.\mathrm{H}_{2} \mathrm{O}\right) \lambda_{\max } 256.5 \mathrm{~nm}(\varepsilon$ 7,600, pH 2). $258.0 \mathrm{~nm}(\varepsilon 7,200, \mathrm{pH} 7), 263.0$ $\mathrm{nm}(\varepsilon 7,600, \mathrm{pH} 11) ;{ }^{1} \mathrm{H}$ NMR $\left(\mathrm{MeOH}-d_{4}\right) \delta 8.91(\mathrm{~s}, 1 \mathrm{H}), 8.02(\mathrm{~s}, 1 \mathrm{H}), 6.36(\mathrm{~d}, J=5.9 \mathrm{~Hz}$, $1 \mathrm{H}), 3.83(\mathrm{dd}, J=11.7,4.9 \mathrm{~Hz}, 1 \mathrm{H}), 3.78(\mathrm{dd}, J=11.7,4.9 \mathrm{~Hz}, 1 \mathrm{H}), 3.77 \sim 3.70(\mathrm{~m}, 2 \mathrm{H}), 3.60$ (q, $J=4.9 \mathrm{~Hz}, 1 \mathrm{H}$ ), 3.48 (quin, $J=5.9 \mathrm{~Hz}, 1 \mathrm{H}$ ); Anal. $\left(\mathrm{C}_{10} \mathrm{H}_{12} \mathrm{~N}_{4} \mathrm{O}_{3} \mathrm{~S}\right) \mathrm{C}, \mathrm{H}, \mathrm{N}, \mathrm{S}$.

\section{9-[(2R,3S,4R)-2,3-dihydroxymethyl-thietan-4-yl]-guanine (35)}

See the procedure of compound $\mathbf{2 2}$ for deprotection reaction with $1 \mathrm{M} \mathrm{TBAF}$ solution. The title compound 35 was obtained on 0.132 -mmol scale in $91 \%$ yield: $\mathrm{mp}>200^{\circ} \mathrm{C}\left(\mathrm{dec}\right.$.); $[\alpha]^{23}{ }_{\mathrm{D}}-73.7$ ${ }^{\circ}$ (c 0.11, DMSO); UV( $\left.\mathrm{H}_{2} \mathrm{O}\right) \lambda_{\max } 251.5 \mathrm{~nm}(\varepsilon$ 7,300, pH 2). $266.0 \mathrm{~nm}(\varepsilon$ 6,900, pH 7), 266.0 $\mathrm{nm}(\varepsilon 7,100, \mathrm{pH} 11) ;{ }^{1} \mathrm{H}$ NMR (DMSO- $\left.d_{6}\right) \delta 13.48(\mathrm{br} \mathrm{s}, 1 \mathrm{H}), 8.79(\mathrm{~s}, 1 \mathrm{H}), 6.23(\mathrm{~d}, J=6.8$ $\mathrm{Hz}, 1 \mathrm{H}), 5.07$ (t, J = 4.9 Hz, 1H), 4.99 (br s, 1H), 3.79 3.46 (m, 5H), 3.30 2.26 (m, 1H); Anal. $\left(\mathrm{C}_{10} \mathrm{H}_{13} \mathrm{~N}_{5} \mathrm{O}_{3} \mathrm{~S}\right) \mathrm{C}, \mathrm{H}, \mathrm{N}, \mathrm{S}$.

\section{(-)-[2R,3R,4S,5S]-Methanesulfonic acid 5-methanesulfonyloxymethyl-2,2-dimethyl- tetrahydro-furo[2,3-d][1,3]dioxol-6-yl ester (37)}

Using the same procedure described for the preparation of compound $\mathbf{3}$, the title compound was prepared on a $81.6 \mathrm{mmol}$ scale in $90 \%$ yield as white solid: $\mathrm{mp} 115 \sim 116^{\circ} \mathrm{C} ;[\alpha]^{22} \mathrm{D}-80.2$ ${ }^{\circ}\left(\mathrm{c} 0.57, \mathrm{CHCl}_{3}\right) ;{ }^{1} \mathrm{H}$ NMR $\left(\mathrm{CDCl}_{3}\right) \delta 5.84(\mathrm{~d}, J=3.4 \mathrm{~Hz}, 1 \mathrm{H}), 4.82 \sim 4.74(\mathrm{~m}, 2 \mathrm{H}), 4.55(\mathrm{dd}$, $J=11.8,1.9 \mathrm{~Hz}, 1 \mathrm{H}), 4.41 \sim 4.30(\mathrm{~m}, 2 \mathrm{H}), 3.16(\mathrm{~s}, 3 \mathrm{H}), 3.08(\mathrm{~s}, 3 \mathrm{H}), 1.58(\mathrm{~s}, 3 \mathrm{H}), 1.38(\mathrm{~s}, 3 \mathrm{H})$; Anal. $\left(\mathrm{C}_{10} \mathrm{H}_{18} \mathrm{O}_{9} \mathrm{~S}_{2}\right) \mathrm{C}, \mathrm{H}$

\section{(-)-[2R,3R,4S,5S]-Thioacetic acid S-(6-methanesulfonyloxy-2,2-dimethyl-tetrahydro-furo[2,3- d][1,3]dioxol-5-ylmethyl) ester (38)}

Was prepared from compound $\mathbf{3 7}$ on a $14.0 \mathrm{mmol}$ scale in $80 \%$ yield as brownish solid by the same procedure described for 4: $\mathrm{mp} 112 \sim 113^{\circ} \mathrm{C} ;[\alpha]^{23}{ }_{\mathrm{D}}-70.0^{\circ}\left(\mathrm{c} 0.53, \mathrm{CHCl}_{3}\right) ;{ }^{1} \mathrm{H} \mathrm{NMR}$ $\left(\mathrm{CDCl}_{3}\right) \delta 5.77(\mathrm{~d}, J=3.7 \mathrm{~Hz}, 1 \mathrm{H}), 4.75(\mathrm{t}, J=4.2 \mathrm{~Hz}, 1 \mathrm{H}), 4.48(\mathrm{dd}, J=8.8,4.6 \mathrm{~Hz}, 1 \mathrm{H})$, $4.31 \sim 4.25(\mathrm{~m}, 1 \mathrm{H}), 3.35(\mathrm{dd}, J=14.5,4.1 \mathrm{~Hz}, 1 \mathrm{H}), 3.23(J=14.5,5.1 \mathrm{~Hz}, 1 \mathrm{H}), 3.16(\mathrm{~s}, 3 \mathrm{H})$, $2.36(\mathrm{~s}, 3 \mathrm{H}), 1.55(\mathrm{~s}, 3 \mathrm{H}), 1.34(\mathrm{~s}, 3 \mathrm{H})$; Anal. $\left(\mathrm{C}_{11} \mathrm{H}_{18} \mathrm{O}_{7} \mathrm{~S}_{2}\right) \mathrm{C}, \mathrm{H}, \mathrm{S}$. 


\section{(-)-4,4-Dimethyl-tetrahydro-3,5,6-trioxa-2-thia-cyclobuta[a]pentalene (39)}

Was prepared from compound $\mathbf{3 8}$ on a $30.85 \mathrm{mmol}$ scale in $95 \%$ yield as yellowish oil by the same procedure described for 5: $[\alpha]^{23}{ }_{\mathrm{D}}-89.4^{\circ}\left(\mathrm{c} 1.76, \mathrm{CH}_{2} \mathrm{Cl}_{2}\right) ;{ }^{1} \mathrm{H}$ NMR $\left(\mathrm{CDCl}_{3}\right) \delta 6.41(\mathrm{~d}$, $J=3.4 \mathrm{~Hz}, 1 \mathrm{H}), 5.26(\mathrm{t}, J=5.3 \mathrm{~Hz}, 1 \mathrm{H}), 4.71(\mathrm{~d}, J=3.4 \mathrm{~Hz}, 1 \mathrm{H}), 4.08(\mathrm{~d}, J=5.3 \mathrm{~Hz}, 1 \mathrm{H})$, $3.49(\mathrm{dd}, J=10.6,5.4 \mathrm{~Hz}, 1 \mathrm{H}), 2.84(\mathrm{~d}, J=10.6 \mathrm{~Hz}, 1 \mathrm{H}), 1.43(\mathrm{~s}, 3 \mathrm{H}), 1.36(\mathrm{~s}, 3 \mathrm{H})$; Anal. $\left(\mathrm{C}_{8} \mathrm{H}_{12} \mathrm{O}_{3} \mathrm{~S}\right) \mathrm{C}, \mathrm{H}, \mathrm{S}$.

\section{(-)-2-Oxa-6-thia-bicyclo[3.2.0]heptane-3,4-diol (40)}

Was prepared from compound $\mathbf{3 9}$ on a $27.77 \mathrm{mmol}$ scale in $90 \%$ yield as yellowish oil (anomeric mixture) by the same procedure described for $\mathbf{6}$.

\section{(-)-[2R,3S]-2-Hydroxymethyl-thietan-3-ol (41)}

Was prepared from compound $\mathbf{4 0}$ on a $10.11 \mathrm{mmol}$ scale in $70 \%$ yield as yellowish oil by the same procedure described for 7: $[\alpha]^{24} \mathrm{D}-173.5^{\circ}(\mathrm{c} 0.84, \mathrm{MeOH}) ;{ }^{1} \mathrm{H} \mathrm{NMR}\left(\mathrm{CDCl}_{3}\right) \delta 5.00$ (quin. $J=8.1 \mathrm{~Hz}, 1 \mathrm{H}), 4.09 \sim 3.98(\mathrm{~m}, 2 \mathrm{H}), 3.85(\mathrm{~d}, J=8.9 \mathrm{~Hz}, 1 \mathrm{H}), 3.76 \sim 3.71(\mathrm{~m}, 1 \mathrm{H})$, 3.37 3.24 (m, 3H); Anal. $\left(\mathrm{C}_{4} \mathrm{H}_{8} \mathrm{O}_{2} \mathrm{~S} \cdot 0.35 \mathrm{H}_{2} \mathrm{O}\right) \mathrm{C}, \mathrm{H}, \mathrm{S}$.

\section{(-)-[2R,3R]-2-(tert-Butyl-diphenyl-silanyloxymethyl)-thietan-3-ol (42)}

Was prepared from compound $\mathbf{4 1}$ on a $17.10 \mathrm{mmol}$ scale in $85 \%$ yield as yellowish oil by the same procedure described for 8: $[\alpha]^{22_{\mathrm{D}}}-78.6^{\circ}\left(\mathrm{c} 0.68, \mathrm{CHCl}_{3}\right) ;{ }^{1} \mathrm{H} \mathrm{NMR}\left(\mathrm{CDCl}_{3}\right) \delta 7.84 \sim 7.38$ (m, 10H), 5.06 (quin, $J=8.1 \mathrm{~Hz}, 1 \mathrm{H}), 4.19 \sim 4.10(\mathrm{~m}, 2 \mathrm{H}), 3.88(\mathrm{~d}, J=9.7 \mathrm{~Hz}, 1 \mathrm{H}), 3.73 \sim 3.67$ $(\mathrm{m}, 1 \mathrm{H}), 3.54(\mathrm{t}, J=8.3 \mathrm{~Hz}, 1 \mathrm{H}), 3.33(\mathrm{t}, J=8.3 \mathrm{~Hz}, 1 \mathrm{H}), 1.12(\mathrm{~s}, 9 \mathrm{H})$; Anal. $\left(\mathrm{C}_{20} \mathrm{H}_{26} \mathrm{O}_{2} \mathrm{SSi}\right)$ $\mathrm{C}, \mathrm{H}, \mathrm{S}$.

\section{(-)-[2R]-tert-Butyl-(3-methylene-thietan-2-ylmethoxy)-diphenyl-silane (43)}

Was prepared from compound $\mathbf{4 2}$ on a $5.32 \mathrm{mmol}$ scale in $40 \%$ yield as yellowish oil by the same procedure described for 9: $[\alpha]^{23}{ }_{\mathrm{D}}-71.8^{\circ}\left(\mathrm{c} 1.60, \mathrm{CH}_{2} \mathrm{Cl}_{2}\right) ;{ }^{1} \mathrm{H} \mathrm{NMR}\left(\mathrm{CDCl}_{3}\right) \delta$ $7.72 \sim 7.65(\mathrm{~m}, 4 \mathrm{H}), 7.47 \sim 7.37(\mathrm{~m}, 6 \mathrm{H}), 4.86(\mathrm{~d}, J=2.1 \mathrm{~Hz}, 1 \mathrm{H}), 4.71(\mathrm{~d}, J=2.1 \mathrm{~Hz}, 1 \mathrm{H})$, $4.44 \sim 4.37(\mathrm{~m}, 1 \mathrm{H}), 4.00(\mathrm{dd}, J=10.3,6.8 \mathrm{~Hz}, 1 \mathrm{H}), 3.87(\mathrm{dd}, J=10.3,6.8 \mathrm{~Hz}, 1 \mathrm{H}), 3.84 \sim 3.74$ $(\mathrm{m}, 2 \mathrm{H}), 1.06$ (s, 9H); Anal. $\left(\mathrm{C}_{21} \mathrm{H}_{26} \mathrm{OSSi}\right) \mathrm{C}, \mathrm{H}, \mathrm{S}$.

\section{(-)-[2R,3R]-[2-(tert-Butyl-diphenyl-silanyloxymethyl)-thietan-3-yl]-methanol (44)}

Was prepared from compound $\mathbf{4 3}$ on a $4.43 \mathrm{mmol}$ scale in $64 \%$ yield as yellowish oil by the same procedure described for 10: $[\alpha]^{22} \mathrm{D}-32.1^{\circ}\left(\mathrm{c} 0.82, \mathrm{CHCl}_{3}\right) ;{ }^{1} \mathrm{H} \mathrm{NMR}\left(\mathrm{CDCl}_{3}\right) \delta$ $7.78 \sim 7.32(\mathrm{~m}, 10 \mathrm{H}), 4.28(\mathrm{t}, J=10.1 \mathrm{~Hz}, 1 \mathrm{H}), 4.01(\mathrm{t}, J=9.9 \mathrm{~Hz}, 1 \mathrm{H}), 3.80 \sim 3.42(\mathrm{~m}, 5 \mathrm{H})$, 3.02 2.83 (m, 2H), 1.07 (s, 9H); Anal. $\left(\mathrm{C}_{21} \mathrm{H}_{28} \mathrm{O}_{2} \mathrm{SSi}\right) \mathrm{C}, \mathrm{H}, \mathrm{S}$.

\section{(-)-[2R,3S]-[2-(tert-Butyl-diphenyl-silanyloxymethyl)-thietan-3-yl]-methanol (45)}

Was prepared from compound $\mathbf{4 4}$ on a $2.27 \mathrm{mmol}$ scale in $45 \%$ yield as yellowish oil by the same procedure described for 11: $[\alpha]^{22}{ }_{\mathrm{D}}-39.5^{\circ}\left(\mathrm{c} 0.91, \mathrm{CH}_{2} \mathrm{Cl}_{2}\right) ;{ }^{1} \mathrm{H} \mathrm{NMR}\left(\mathrm{CDCl}_{3}\right) \delta$ 7.70 7.36 (m, 10H), 3.82 3.58 (m, 5H), 3.22 3.10 (m, 1H), 3.01 2.93 (m, 2H), $1.06(\mathrm{~s}, 9 \mathrm{H})$; Anal. $\left(\mathrm{C}_{21} \mathrm{H}_{28} \mathrm{O}_{2} \mathrm{SSi}\right) \mathrm{C}, \mathrm{H}, \mathrm{S}$.

\section{(-)-[2R,3S]-2,3-Bis-(tert-butyl-diphenyl-silanyloxymethyl)-thietane (46)}

Was prepared from compound $\mathbf{4 5}$ on a $2.16 \mathrm{mmol}$ scale in $92 \%$ yield as yellowish oil by the same procedure described for 12: $[\alpha]^{24} \mathrm{D}-44.7^{\circ}\left(\mathrm{c} 0.43, \mathrm{CH}_{2} \mathrm{Cl}_{2}\right) ;{ }^{1} \mathrm{H} \mathrm{NMR}\left(\mathrm{CDCl}_{3}\right) \delta$ $7.70 \sim 7.33(\mathrm{~m}, 20 \mathrm{H}), 3.90(\mathrm{dd}, J=9.7,6.1 \mathrm{~Hz}, 1 \mathrm{H}), 3.77(\mathrm{dd}, J=10.2,6.6 \mathrm{~Hz}, 1 \mathrm{H}), 3.73 \sim 3.65$ (m, 3H), 3.16 2.95 (m, 3H), 1.05 (s, 9H), 1.04 (s, 9H); Anal. $\left(\mathrm{C}_{37} \mathrm{H}_{46} \mathrm{O}_{2} \mathrm{SSi}_{2}\right) \mathrm{C}, \mathrm{H}, \mathrm{S}$. 
1-[(2S,3R,4R/S)-2,3-Bis-(tert-butyl-diphenyl-silanyloxymethyl)-thietan-4-yl]-thymine (47)

Was prepared from the coupling of sulfoxide which was obtained from the oxidation of compound 46 with silylated thymine on a $0.18 \mathrm{mmol}$ scale in $44 \%$ yield $(\alpha / \beta$ mixture, $\alpha: \beta=$ $1: 3$ as determined by NMR) as by the same procedure described for $13: \mathrm{UV}\left(\mathrm{CH}_{2} \mathrm{Cl}_{2}\right) \lambda_{\max }$ $270.0 \mathrm{~nm}$; Anal. $\left(\mathrm{C}_{42} \mathrm{H}_{50} \mathrm{~N}_{2} \mathrm{O}_{4} \mathrm{SSi}_{2}\right) \mathrm{C}, \mathrm{H}, \mathrm{N}, \mathrm{S}$.

\section{1-[(2S,3R,4R/S)-2,3-Bis-(tert-butyl-diphenyl-silanyloxymethyl)-thietan-4-yl]-uracil (48)}

Using the similar condensation procedure for the preparation of compound 13. The title compound 48 was obtained on $0.325-\mathrm{mmol}$ scale in $40 \%$ yield as a $\alpha / \beta$ mixture $(\alpha: \beta=1: 2$ as determined by NMR): $\mathrm{UV}\left(\mathrm{CH}_{2} \mathrm{Cl}_{2}\right) \lambda_{\max } 265.0 \mathrm{~nm}$; Anal. $\left(\mathrm{C}_{41} \mathrm{H}_{48} \mathrm{~N}_{2} \mathrm{O}_{4} \mathrm{SSi}_{2}\right) \mathrm{C}, \mathrm{H}, \mathrm{N}, \mathrm{S}$.

1-[(2S,3R,4R/S)-2,3-Bis-(tert-butyl-diphenyl-silanyloxymethyl)-thietan-4-yl]-cytosine (49)

Using the similar condensation procedure for the preparation of compound 15 . The title compound 49 was obtained on $0.16-\mathrm{mmol}$ scale in $75 \%$ yield as a $\alpha / \beta$ mixture: $\mathrm{UV}\left(\mathrm{CH}_{2} \mathrm{Cl}_{2}\right)$ $\lambda_{\max } 285.5 \mathrm{~nm}$; Anal. $\left(\mathrm{C}_{41} \mathrm{H}_{49} \mathrm{~N}_{3} \mathrm{O}_{3} \mathrm{SSi}_{2}\right) \mathrm{C}, \mathrm{H}, \mathrm{N}, \mathrm{S}$.

\section{1-[(2S,3R,4S)-2,3-dihydroxymethyl-thietan-4-yl]-thymine (50)}

Was prepared from compound 47 on a $0.043 \mathrm{mmol}$ scale in $63 \%$ yield as white solid by the same procedure described for $22: \mathrm{mp}>200^{\circ} \mathrm{C}\left(\mathrm{dec}\right.$.); $[\alpha]^{26_{\mathrm{D}}} 82.8^{\circ}$ (c 0.13 , DMSO); $\mathrm{UV}\left(\mathrm{H}_{2} \mathrm{O}\right)$ $\lambda_{\max } 264.0 \mathrm{~nm}(\varepsilon 9,400, \mathrm{pH} 2) .262 .0 \mathrm{~nm}(\varepsilon 9,900, \mathrm{pH} 7), 265.5 \mathrm{~nm}(\varepsilon 7,100, \mathrm{pH} 11) ;{ }^{1} \mathrm{H}$ NMR $(\mathrm{MeOH}) \delta 8.30(\mathrm{~s}, 1 \mathrm{H}), 6.08(\mathrm{~d}, J=6.8 \mathrm{~Hz}, 1 \mathrm{H}), 3.76(\mathrm{dd}, J=11.7,3.9 \mathrm{~Hz}, 1 \mathrm{H}), 3.72(\mathrm{dd}, J$ $=11.7,4.9 \mathrm{~Hz}, 1 \mathrm{H}), 3.58(\mathrm{~d}, J=3.9 \mathrm{~Hz}, 2 \mathrm{H}), 3.54 \sim 3.49(\mathrm{~m}, 1 \mathrm{H}), 3.32 \sim 3.26(\mathrm{~m}, 1 \mathrm{H}), 1.95(\mathrm{~s}$, $3 \mathrm{H})$; Anal. $\left(\mathrm{C}_{10} \mathrm{H}_{14} \mathrm{~N}_{2} \mathrm{O}_{4} \mathrm{~S}\right) \mathrm{C}, \mathrm{H}, \mathrm{N}, \mathrm{S}$.

\section{1-[(2S,3R,4S)-2,3-dihydroxymethyl-thietan-4-yl]-uracil (51)}

Was prepared from compound $\mathbf{4 8}$ on a $0.043 \mathrm{mmol}$ scale in $59 \%$ yield as white solid by the same procedure described for $23: \mathrm{mp}>200^{\circ} \mathrm{C}\left(\mathrm{dec}\right.$.); $[\alpha]^{24}{ }_{\mathrm{D}} 33.2^{\circ}(\mathrm{c} 0.23, \mathrm{MeOH}) ; \mathrm{UV}\left(\mathrm{H}_{2} \mathrm{O}\right)$ $\lambda_{\max } 265.5 \mathrm{~nm}(\varepsilon 9,200, \mathrm{pH} 2), 265.5 \mathrm{~nm}(\varepsilon 8,500, \mathrm{pH} 7), 265.5 \mathrm{~nm}(\varepsilon 6,900, \mathrm{pH} 11) ;{ }^{1} \mathrm{H}$ NMR $(\mathrm{MeOH}) \delta 8.46(\mathrm{~d}, \mathrm{~J}=7.8 \mathrm{~Hz}, 1 \mathrm{H}), 6.07(\mathrm{~d}, \mathrm{~J}=6.8 \mathrm{~Hz}, 1 \mathrm{H}), 5.81(\mathrm{~d}, \mathrm{~J}=7.8 \mathrm{~Hz}, 1 \mathrm{H}), 3.76(\mathrm{dd}$, $\mathrm{J}=\mathrm{Hz}, 1 \mathrm{H}), 3.71(\mathrm{dd}, \mathrm{J}=\mathrm{Hz}, 1 \mathrm{H}), 3.60(\mathrm{~d}, \mathrm{~J}=\mathrm{Hz}, 2 \mathrm{H}), 3.54 \sim 3.49(\mathrm{~m}, 1 \mathrm{H}), 3.28 \sim 3.21(\mathrm{~m}$, $1 \mathrm{H})$; Anal. $\left(\mathrm{C}_{9} \mathrm{H}_{12} \mathrm{~N}_{2} \mathrm{O}_{4} \mathrm{~S}\right) \mathrm{C}, \mathrm{H}, \mathrm{N}, \mathrm{S}$.

\section{1-[(2S,3R,4S)-2,3-dihydroxymethyl-thietan-4-yl]-cytosine (52)}

Was prepared from compound 49 on a $0.043 \mathrm{mmol}$ scale in $56 \%$ yield as white solid by the same procedure described for 24 : $\mathrm{mp} 126 \sim 127^{\circ} \mathrm{C}$; $[\alpha]^{25}{ }_{\mathrm{D}} 61.7^{\circ}(\mathrm{c} 0.11, \mathrm{MeOH}) ; \mathrm{UV}\left(\mathrm{H}_{2} \mathrm{O}\right)$ $\lambda_{\max } 282.5 \mathrm{~nm}(\varepsilon 12,500, \mathrm{pH} 2), 274.5 \mathrm{~nm}(\varepsilon 9,700, \mathrm{pH} 7), 275.5 \mathrm{~nm}(\varepsilon 9,600, \mathrm{pH} 11) ;{ }^{1} \mathrm{H}$ NMR (MeOH) $\delta 8.43(\mathrm{~d}, J=6.8 \mathrm{~Hz}, 1 \mathrm{H}), 6.04(\mathrm{~s}, J=6.8 \mathrm{~Hz}, 1 \mathrm{H}), 6.00(\mathrm{~d}, J=7.8 \mathrm{~Hz}, 1 \mathrm{H})$, $3.75(\mathrm{dd}, J=11.7,4.9 \mathrm{~Hz}, 1 \mathrm{H}), 3.69(\mathrm{dd}, J=11.7,5.6 \mathrm{~Hz}, 1 \mathrm{H}), 3.66 \sim 3.58(\mathrm{~m}, 1 \mathrm{H}), 3.51 \sim 3.47$ (m, $1 \mathrm{H}$ ), 3.14 (quin, $J=6.8 \mathrm{~Hz}, 1 \mathrm{H}$ ); Anal. $\left(\mathrm{C}_{9} \mathrm{H}_{12} \mathrm{~N}_{2} \mathrm{O}_{4} \mathrm{~S}\right) \mathrm{C}, \mathrm{H}, \mathrm{N}, \mathrm{S}$.

\section{9-[(2S,3R,4S)-2,3-Bis-(tert-butyl-diphenyl-silanyloxymethyl)-thietan-4-yl]-6-chloropurine} (53)

Using the same condensation procedure for the preparation of compound $\mathbf{2 8}$, the title compounds $\mathbf{5 3}$ was obtained on $0.370-\mathrm{mmol}$ scale in $40 \%$ yield as well as its $\alpha$ anomer with the ratio of $\alpha: \beta=4: 5 .[\alpha]^{22} \mathrm{D}-16.8^{\circ}\left(\mathrm{c} 0.58, \mathrm{CHCl}_{3}\right) ; \mathrm{UV}\left(\mathrm{CH}_{2} \mathrm{Cl}_{2}\right) \lambda_{\max } 264.5 \mathrm{~nm} ;{ }^{1} \mathrm{H} \mathrm{NMR}$ $\left(\mathrm{CDCl}_{3}\right) \delta 8.87(\mathrm{~s}, 1 \mathrm{H}), 8.86(\mathrm{~s}, 1 \mathrm{H}), 7.66 \sim 7.27(\mathrm{~m}, 20 \mathrm{H}), 6.56(\mathrm{~d}, J=7.1 \mathrm{~Hz}, 1 \mathrm{H}), 3.82 \sim 3.62$ (m, 5H), 3.39 3.31 (m, 1H), $1.06(\mathrm{~s}, 9 \mathrm{H}), 1.02(\mathrm{~s}, 9 \mathrm{H})$; Anal. $\left(\mathrm{C}_{42} \mathrm{H}_{47} \mathrm{ClN}_{4} \mathrm{O}_{2} \mathrm{SSi}_{2}\right) \mathrm{C}, \mathrm{H}, \mathrm{N}$, S. 


\section{9-[(2S,3R,4S)-2,3-Bis-(tert-butyl-diphenyl-silanyloxymethyl)-thietan-4-yl]-6-chloro2- fluoropurine (54)}

Using the same condensation procedure of compound 29, the title compound $\mathbf{5 4}$ was obtained on $0.797-\mathrm{mmol}$ scale in $23 \%$ yield together with its $\alpha$ anomer $(\alpha: \beta=4: 5):[\alpha]^{24} \mathrm{D}-10.1^{\circ}$ (c $\left.0.54, \mathrm{CHCl}_{3}\right) ; \mathrm{UV}\left(\mathrm{CH}_{2} \mathrm{Cl}_{2}\right) \lambda_{\max } 254 \mathrm{~nm} ;{ }^{1} \mathrm{H} \mathrm{NMR}\left(\mathrm{CDCl}_{3}\right) \delta 8.85(\mathrm{~s}, 1 \mathrm{H}), 7.64 \sim 7.24(\mathrm{~m}$, $20 \mathrm{H}), 6.47$ (d, $J=6.8 \mathrm{~Hz}, 1 \mathrm{H}), 3.83 \sim 3.65(\mathrm{~m}, 5 \mathrm{H}), 3.36 \sim 3.28(\mathrm{~m}, 1 \mathrm{H}), 1.06(\mathrm{~s}, 9 \mathrm{H}), 1.03(\mathrm{~s}$, $9 \mathrm{H})$; Anal. $\left(\mathrm{C}_{42} \mathrm{H}_{46} \mathrm{ClFN}_{4} \mathrm{O}_{2} \mathrm{SSi}_{2}\right) \mathrm{C}, \mathrm{H}, \mathrm{N}, \mathrm{S}$.

\section{9-[(2S,3R,4S)-2,3-Bis-(tert-butyl-diphenyl-silanyloxymethyl)-thietan-4-yl]-adenine (55)}

Was prepared from compound $\mathbf{5 3}$ on a $0.078 \mathrm{mmol}$ scale in $74 \%$ yield as white solid by the same procedure described for 30: $[\alpha]^{23} \mathrm{D}-40.7^{\circ}\left(\mathrm{c} 0.15, \mathrm{CH}_{2} \mathrm{Cl}_{2}\right)$; $\mathrm{UV}\left(\mathrm{CH}_{2} \mathrm{Cl}_{2}\right) \lambda_{\max } 272.0$ $\mathrm{nm} ;{ }^{1} \mathrm{H}$ NMR $\left(\mathrm{CDCl}_{3}\right) \delta 8.44(\mathrm{~s}, 1 \mathrm{H}), 7.85(\mathrm{~s}, 1 \mathrm{H}), 7.66 \sim 7.30(\mathrm{~m}, 20 \mathrm{H}), 6.06(\mathrm{br} \mathrm{s}, 2 \mathrm{H}), 6.03$ $(\mathrm{d}, J=8.6 \mathrm{~Hz}, 1 \mathrm{H}) ; 3.91 \sim 3.83(\mathrm{~m}, 2 \mathrm{H}), 3.74 \sim 3.54(\mathrm{~m}, 3 \mathrm{H}), 3.43 \sim 3.34(\mathrm{~m}, 1 \mathrm{H}), 1.09(\mathrm{~s}, 9 \mathrm{H})$, 1.05 (s, 9H); Anal. $\left(\mathrm{C}_{42} \mathrm{H}_{49} \mathrm{~N}_{5} \mathrm{O}_{2} \mathrm{SSi}_{2}\right) \mathrm{C}, \mathrm{H}, \mathrm{N}, \mathrm{S}$.

\section{9-[(2S,3R,4S)-2,3-Bis-(tert-butyl-diphenyl-silanyloxymethyl)-thietan-4-yl]-hypoxanthine (56)}

Was prepared from compound $\mathbf{5 3}$ on a $0.11 \mathrm{mmol}$ scale in $84 \%$ yield as white solid by the same procedure described for 31: $[\alpha]^{24}{ }_{\mathrm{D}} 26.9^{\circ}\left(\mathrm{c} 0.13, \mathrm{CH}_{2} \mathrm{Cl}_{2}\right) ; \mathrm{UV}\left(\mathrm{CH}_{2} \mathrm{Cl}_{2}\right) \lambda_{\max } 262.5$ $\mathrm{nm} ;{ }^{1} \mathrm{H}$ NMR $\left(\mathrm{CDCl}_{3}\right) \delta 8.45(\mathrm{~s}, 1 \mathrm{H}), 7.72(\mathrm{~s}, 1 \mathrm{H}), 7.68 \sim 7.12(\mathrm{~m}, 20 \mathrm{H}), 6.56(\mathrm{~d}, J=5.9 \mathrm{~Hz}$, $1 \mathrm{H}), 3.89(\mathrm{dd} J=10.7,5.9 \mathrm{~Hz}, 1 \mathrm{H}), 3.85 \sim 3.68(\mathrm{~m}, 4 \mathrm{H}), 3.39 \sim 3.32(\mathrm{~m}, 1 \mathrm{H}), 1.05(\mathrm{~s}, 9 \mathrm{H}), 1.01$ (s, 9H); Anal. $\left(\mathrm{C}_{42} \mathrm{H}_{48} \mathrm{~N}_{4} \mathrm{O}_{3} \mathrm{SSi}_{2}\right) \mathrm{C}, \mathrm{H}, \mathrm{N}, \mathrm{S}$.

\section{9-[(2S,3R,4S)-2,3-Bis-(tert-butyl-diphenyl-silanyloxymethyl)-thietan-4-yl]-guanine (57)}

Was prepared from compound $\mathbf{5 4}$ on a $0.11 \mathrm{mmol}$ scale in $84 \%$ yield as white solid by the same procedure described for 32: $[\alpha]^{22_{\mathrm{D}}} 17.8^{\circ}\left(\mathrm{c} 0.29, \mathrm{CHCl}_{3}\right) ; \mathrm{UV}\left(\mathrm{CH}_{2} \mathrm{Cl}_{2}\right) \lambda_{\max } 264.0$ $\mathrm{nm} ;{ }^{1} \mathrm{H}$ NMR $\left(\mathrm{CDCl}_{3}\right) \delta 8.36(\mathrm{~s}, 1 \mathrm{H}), 7.75 \sim 7.24(\mathrm{~m}, 20 \mathrm{H}), 6.36(\mathrm{~d}, J=6.8 \mathrm{~Hz}, 1 \mathrm{H})$, 3.95 3.63 (m, 5H), 3.37 3.30 (m, 1H), 1.04 (s, 9H), 0.99 (s, 9H); Anal. $\left(\mathrm{C}_{42} \mathrm{H}_{49} \mathrm{~N}_{5} \mathrm{O}_{3} \mathrm{SSi}_{2}\right)$ $\mathrm{C}, \mathrm{H}, \mathrm{N}, \mathrm{S}$.

\section{9-[(2S,3R,4S)-2,3-dihydroxymethyl-thietan-4-yl]-adenine (58)}

Using the same procedure for deprotection of compound $\mathbf{3 3}$, the title compound $\mathbf{5 8}$ was obtained on $0.094-\mathrm{mmol}$ scale in $84 \%$ yield: $\mathrm{mp}>200^{\circ} \mathrm{C}$; $[\alpha]^{25} \mathrm{D}-93.3^{\circ}(\mathrm{c} 0.11, \mathrm{MeOH})$; UV $\left(\mathrm{H}_{2} \mathrm{O}\right) \lambda_{\max } 272.5 \mathrm{~nm}(\varepsilon 15,000, \mathrm{pH} 2) .270 .5 \mathrm{~nm}(\varepsilon 10,000, \mathrm{pH} 7), 271.5 \mathrm{~nm}(\varepsilon 10,000, \mathrm{pH}$ $11) ;{ }^{1} \mathrm{H}$ NMR $(\mathrm{MeOH}) \delta 8.84(\mathrm{~s}, 1 \mathrm{H}), 8.24(\mathrm{~s}, 1 \mathrm{H}), 6.17(\mathrm{~d}, J=6.6 \mathrm{~Hz}, 1 \mathrm{H}), 3.80(\mathrm{~d}, J=4.6$ $\mathrm{Hz}, 2 \mathrm{H}), 3.73(\mathrm{dd}, J=11.7,6.6 \mathrm{~Hz}, 1 \mathrm{H}), 3.69(\mathrm{dd}, J=11.7,5.1 \mathrm{~Hz}, 1 \mathrm{H}), 3.62 \sim 3.56(\mathrm{~m}, 1 \mathrm{H})$, 3.55 3.48 (m, 1H); Anal. $\left(\mathrm{C}_{10} \mathrm{H}_{13} \mathrm{~N}_{5} \mathrm{O}_{2} \mathrm{~S}\right) \mathrm{C}, \mathrm{H}, \mathrm{N}, \mathrm{S}$.

\section{9-[(2S,3R,4S)-2,3-dihydroxymethyl-thietan-4-yl]-hypoxanthine (59)}

Using the same procedure for the deprotection of compound $\mathbf{3 3}$, the title compound $\mathbf{5 9}$ was obtained on 0.145 -mmol scale in $86 \%$ yield: $\mathrm{mp} 213 \sim 214^{\circ} \mathrm{C} ;[\alpha]^{27}{ }_{\mathrm{D}}-23.9^{\circ}(\mathrm{c} 0.15, \mathrm{MeOH})$; $\mathrm{UV}\left(\mathrm{H}_{2} \mathrm{O}\right) \lambda_{\max } 256.5 \mathrm{~nm}(\varepsilon 7,600, \mathrm{pH} 2) .258 .0 \mathrm{~nm}(\varepsilon 7,200, \mathrm{pH} 7), 263.0 \mathrm{~nm}(\varepsilon 7,600, \mathrm{pH}$ $11) ;{ }^{1} \mathrm{H}$ NMR $\left(\mathrm{MeOH}-d_{4}\right) \delta 8.91(\mathrm{~s}, 1 \mathrm{H}), 8.02(\mathrm{~s}, 1 \mathrm{H}), 6.36(\mathrm{~d}, J=5.9 \mathrm{~Hz}, 1 \mathrm{H}), 3.83(\mathrm{dd}, J=$ $11.7,4.9 \mathrm{~Hz}, 1 \mathrm{H}), 3.78(\mathrm{dd}, J=11.7,4.9 \mathrm{~Hz}, 1 \mathrm{H}), 3.77 \sim 3.70(\mathrm{~m}, 2 \mathrm{H}), 3.60(\mathrm{q}, J=4.9 \mathrm{~Hz}, 1 \mathrm{H})$, 3.48 (quin, $J=5.9 \mathrm{~Hz}, 1 \mathrm{H}$ ); Anal. $\left(\mathrm{C}_{10} \mathrm{H}_{12} \mathrm{~N}_{4} \mathrm{O}_{3} \mathrm{~S}\right) \mathrm{C}, \mathrm{H}, \mathrm{N}, \mathrm{S}$.

\section{9-[(2S,3R,4S)-2,3-dihydroxymethyl-thietan-4-yl]-guanine (60)}

Using the same procedure for the deprotection of compound 25, the title compound $\mathbf{3 5}$ was obtained on $0.124-\mathrm{mmol}$ scale in $86 \%$ yield: $\mathrm{mp}>200^{\circ} \mathrm{C}$ (dec.); $[\alpha]^{23}{ }_{\mathrm{D}} 70.7^{\circ}$ (c 0.12 , DMSO); $\mathrm{UV}\left(\mathrm{H}_{2} \mathrm{O}\right) \lambda_{\max } 251.5 \mathrm{~nm}(\varepsilon 7,300, \mathrm{pH} 2) .266 .0 \mathrm{~nm}(\varepsilon 6,900, \mathrm{pH} 7), 266.0 \mathrm{~nm}(\varepsilon 7,100, \mathrm{pH}$ 11); ${ }^{1} \mathrm{H}$ NMR (DMSO- $\left.d_{6}\right) \delta 13.48$ (br s, 1H), $8.79(\mathrm{~s}, 1 \mathrm{H}), 6.23(\mathrm{~d}, J=6.8 \mathrm{~Hz}, 1 \mathrm{H}), 5.07$ (t, J 
$=4.9 \mathrm{~Hz}, 1 \mathrm{H}), 4.99(\mathrm{br} \mathrm{s}, 1 \mathrm{H}), 3.79 \sim 3.46(\mathrm{~m}, 5 \mathrm{H}), 3.30 \sim 2.26(\mathrm{~m}, 1 \mathrm{H})$; Anal. $\left(\mathrm{C}_{10} \mathrm{H}_{13} \mathrm{~N}_{5} \mathrm{O}_{3} \mathrm{~S}\right)$ $\mathrm{C}, \mathrm{H}, \mathrm{N}, \mathrm{S}$.

\section{Antiviral Assay}

Human peripheral blood mononuclear (PBM) cells (obtained from Atlanta Red Cross) were isolated by Ficoll-Hypaque discontinuous gradient centrifugation from healthy seronegative donors. Cells were stimulated with phytohemagglutinin A (Difco, Sparks, MD) for 2-3 days prior to use. HIV-1 LAI obtained from the Centers for Disease Control and Prevention (Atlanta, GA) was used as the standard reference virus for the antiviral assays. The molecular infectious clones HIV-1 $1_{\text {xxBru }}$ was obtained from Dr. John Mellors (University of Pittsburgh). Infections were done in bulk for one hour, either with $100 \mathrm{TCID}_{50} / 1 \times 10^{7}$ cells for a flask (T25) assay or with $200 \mathrm{TCID}_{50} / 6 \times 10^{5}$ cells/well for a 24 well plate assay. Cells were added to a plate or flask containing a ten-fold serial dilution of the test compound. Assay medium was RPMI-1640 supplemented with heat inactivated $16 \%$ fetal bovine serum, $1.6 \mathrm{mM} \mathrm{L}$-glutamine, $80 \mathrm{IU} / \mathrm{ml}$ penicillin, $80 \mu \mathrm{g} / \mathrm{ml}$ streptomycin, $0.0008 \%$ DEAE-Dextran, $0.045 \%$ sodium bicarbonate, and $26 \mathrm{IU} / \mathrm{ml}$ recombinant interleukin-2 (Chiron Corp, Emeryville, CA). AZT was used as a positive control for the assay. Untreated and uninfected PBM cells were grown in parallel at equivalent cell concentrations as controls. The cell cultures were maintained in a humidified $5 \% \mathrm{CO}_{2}$-air at $37^{\circ} \mathrm{C}$ for 5 days and supernatants were collected for reverse transcriptase (RT) activity.

Supernatants were centrifuged at $12,000 \mathrm{rpm}$ for $2 \mathrm{~h}$ to pellet the virus. The pellet was solubilized with vortexing in $100 \mu \mathrm{l}$ virus solubilization buffer (VSB) containing $0.5 \%$ Triton $\mathrm{X}-100,0.8 \mathrm{M} \mathrm{NaCl}, 0.5 \mathrm{mM}$ phenylmethylsulfonyl fluoride, $20 \%$ glycerol, and $0.05 \mathrm{M}$ Tris, $\mathrm{pH}$ 7.8. Ten $\mu \mathrm{l}$ of each sample were added to $75 \mu \mathrm{l}$ RT reaction mixture $(0.06 \mathrm{M}$ Tris, $\mathrm{pH} 7.8$, $0.012 \mathrm{M} \mathrm{MgCl}_{2}, 0.006 \mathrm{M}$ dithiothreitol, $0.006 \mathrm{mg} / \mathrm{ml}$ poly $(\mathrm{rA})_{\mathrm{n}}$ oligo $(\mathrm{dT})_{12-18}, 96 \mu \mathrm{g} / \mathrm{ml}$ $\mathrm{dATP}$, and $1 \mu \mathrm{M}$ of $0.08 \mathrm{mCi} / \mathrm{ml}^{3} \mathrm{H}$-thymidine triphosphate (Moravek Biochemicals, Brea, $\mathrm{CA})$ ) and incubated at $37^{\circ} \mathrm{C}$ for $2 \mathrm{~h}$. The reaction was stopped by the addition of $100 \mu 110 \%$ trichloroacetic acid containing $0.05 \%$ sodium pyrophosphate. The acid insoluble product was harvested onto filter paper using a Packard Harvester (Meriden, CT), and the RT activity was read on a Packard Direct Beta Counter (Meriden, CT). The RT results were expressed in counts per minute $(\mathrm{CPM})$ per milliliter. The antiviral $50 \%$ effective concentration $\left(\mathrm{EC}_{50}\right)$ and $90 \%$ effective concentration $\left(\mathrm{EC}_{90}\right)$ were determined from the concentration-response curve using the median effect method. ${ }^{28}$

\section{Cytotoxicity assays}

The compounds were evaluated for their potential toxic effects on uninfected PHA-stimulated human PBM cells, in CEM (T-lymphoblastoid cell line obtained from American Type Culture Collection, Rockville, MD.) and Vero (African green monkey kidney) cells. PBM cells were obtained from whole blood of healthy seronegative donors (HIV-1 and hepatitis B virus) by single-step Ficoll-Hypaque discontinuous gradient centrifugation. Log phase Vero, CEM and PHA-stimulated human PBM cells were seeded at a density of $5 \times 10^{3}, 2.5 \times 10^{3}$ and $5 \times$ $10^{4}$ cells/well respectively. All of the cells were plated in 96-well cell culture plates containing ten-fold serial dilutions of the test drug. The cultures were incubated for 3, 4, and 5 days for Vero, CEM, and PBM cells, respectively in a humidified $5 \% \mathrm{CO}_{2}$-air at $37^{\circ} \mathrm{C}$. At the end of incubation, MTT tetrazolium dye solution (Cell titer $96^{\circledR}$, Promega, Madison, WI) was added to each well and incubated overnight. The reaction was stopped with stop solubilization solution (Promega, Madison, WI). The plates were incubated for $5 \mathrm{~h}$ to ensure that the formazan crystals were dissolved. The plates were read at a wavelength of $570 \mathrm{~nm}$ using an ELISA plate reader (Bio-tek instruments, Inc., Winooski, VT, Model \# EL 312e). The 50\% inhibition concentration $\left(\mathrm{IC}_{50}\right)$ was determined from the concentration-response curve using the median effect method. ${ }^{28}$ 


\section{Molecular modeling studies}

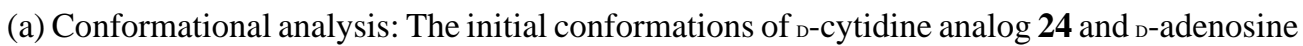
analog 33 were constructed and geometrically-optimized through a Monte Carlo conformational search using MMFF94s force field in Macromodel, version 7.0 (Schrödinger, Inc.). (b) Binding affinity study to HIV-1 reverse transcriptase: All molecular modeling of the enzyme-substrate complexes was carried out using Sybyl 6.7 (Tripos Associates, St. Louis, MO) on a Silicon Graphics Octane2 workstation. The enzyme site of the enzyme-ligand complex was constructed based on the X-ray structure of the covalently trapped catalytic complex of HIV-1 RT with TTP and primer-template duplex (PDB entry 1rtd). A model of the NRTI binding site was constructed which consisted of residues between Lys1 and Pro243 in the p66 subunit, and a 7:4 (template-primer) duplex. The geometrically-optimized structures of each inhibitor, obtained from the geometry optimization study, were used as the initial Cartesian coordinates. The heterocyclic moiety of $n+1^{\text {th }}$ nucleotide in template overhang was modified to the base complementary to the incoming NRTIs. Thus, the adenine moiety which was in the original X-ray structure (1rtd) was modified to guanine. The inhibitor triphosphates were manually docked to the active site of the enzyme by adjusting the torsional angles to those found in the X-ray structure. Gästeiger-Hückel charge was given to the enzyme-ligand complex with formal charges (+2) to two Mg atoms in the active site. Then, Kollman-All-Atom charges were loaded to enzyme site from the biopolymer module in Sybyl. In order to eliminate local strains resulting from merging inhibitors and/or point mutations, residues inside $6 \AA$ from the merged inhibitors and mutated residues were annealed until energy change from one iteration to the next was less than $0.05 \mathrm{kcal} / \mathrm{mol}$. The annealed enzyme-inhibitor complexes were minimized by using Kollman-All-Atom Force Field until iteration number reached 5,000. (c) Binding affinity study to Deoxycytidine Kinase (dCK): All molecular modeling of the enzymesubstrate complexes was carried out using Sybyl 6.7 (Tripos Associates, St. Louis, MO) on a Silicon Graphics Octane 2 workstation. The enzyme site of the enzyme-ligand complex was constructed based on the $\mathrm{X}$-ray structure of the catalytic complex of dCK with $\mathrm{dC}$ and adenosine diphosphate (ADP) (PDB entry: 1P60). ${ }^{26}$ Terminal residues were capped with acetyl and methyl group, $\mathrm{Mg}^{2+}$ atom was added and $\gamma$-phosphate was added. Substrate coordinates of 24 and 52 were constructed and geometrically-optimized through a Monte Carlo conformational search using MMFF94s force field in Macromodel, version 7.0 (Schrödinger, Inc.). Substrates were docked into the binding pocket based on the coordinates of dC.

Gästeiger-Hückel charges and Kollman-All-Atom charge were loaded to the ligands and dCK, respectively, with formal charges $(+2)$ to $\mathrm{Mg}$ atom in the active site. And the residues inside $6 \AA$ (hot region: $6 \AA$, interesting region: $12 \AA$ ) from substrate were annealed until energy change from one iteration to the next was less than $0.05 \mathrm{kcal} / \mathrm{mol}$. The annealed dCK-substrate complex was fully minimized by using the Kollman-All-Atom force field for 5000 iterations.

\section{Supplementary Material}

Refer to Web version on PubMed Central for supplementary material.

\section{Acknowledgements}

This research was supported by the U.S. Public Health Service Grants (AI32351 and AI25899) from the National Institutes of Health.

\section{References}

1. a Petersen EA, Ramirez-Ronda DH, Hardy WD, Schwartz R, Sacks HS, Follansbee S, Peterson DM, Cross A, Anderson RE, Dunkle LM. Dose-related activity of stavudine in patients infected with human immunodeficiency virus. J Infect Dis 1995;171(Suppl 2):S131-S139. [PubMed: 7861018] b Yarchoan R, Pluda JM, Thomas RV, Mitsuya H, Brouwers P, Wyvill KM, Hartman N, Johns DG, Broder S. 
Long-term toxicity/activity profile of 2',3'-dideoxyinosine in AIDS or AIDS-related complex. Lancer 1990;336:526-529.

2. Larder BA. Viral resistance and the selection of antiretroviral combinations. J Acquir Immune Defic Syndr Hum Retrovirol 1995;10(Suppl 1):S28-S33. [PubMed: 8595505]

3. a Schinazi RF. Competitive inhibitors of human immunodeficiency virus reverse transcriptase. Presp Drug Discuss Des 1993;1:151-180. b De Clercq E. Toward improved anti-HIV chemotherapy: Therapeutic strategies for intervention with HIV infections. J Med Chem 1995;38:2492-2517. c el Kouni MH. Trends in the design of nucleoside analogs as anti-HIV drugs. Curr Pham Des 2002;8:581593.

4. a De Clercq E. Strategies in the design of antiviral drugs. Nature Rev 2002;1:12-25. b Herdewijn PAMM. 5-Substituted-2'deoxyuridines as anti-HSV-1 agents: synthesis and structure activity relationship. Antiviral Chem Chemother 1994;5:131-146. c Guenther S, Balzarini J, De Clercq E, Nair V. A Thymidine Phosphorylase-Stable Analogue of BVDU with Significant Antiviral Activity. J Med Chem 2002;45:5426-5429. [PubMed: 12459010]

5. a De Clercq E. Perspectives for the treatment of hepatitis B virus infections. Int J Antimicrob Chemother 1999;12:81-95. and references therein b Gumina G, Song GY, Chu CK. Advances in antiviral agents for hepatitis B virus. Antiviral Chem Chemother 2001;12(Suppl 1):S93-S117. c Hong JH, Choi Y, Chun BK, Chu CK. Current status of anti-HBV chemotherapy. Arch Pharm Res 1998;21:89-105. [PubMed: 9875415]

6. a Snoeck R, Andrei G, De Clercq E. Current pharmacological approaches to the therapy of varicella zoster virus infection: a guide to treatment. Drugs 1999;57:187. [PubMed: 10188760] b Wutzler P. Antiviral therapy of herpes simplex and varicella-zoster virus infections. InterVirology 1997;40:343. [PubMed: 9675639]

7. a McGigan D, Pathirana RN, Snoeck R, Andrei G, De Clercq E, Balzarini J. Discovery of a new family of inhibitors of human cytomegalovirus (HCMV) based upon lipophilic alkyl furano pyrimidine dideoxy nucleosides: Action via a novel non-nucleosidic mechanism. J Med Chem 2004;47:18471851. [PubMed: 15027877] b Faulds D, Heel RC. Ganciclovir: A review of its antiviral activity, pharmacokinetic properties and theraperutic efficacy in cytomegalovirus infections. Drugs 1990;39:597-638. [PubMed: 2161731] c Lea AP, Bryson HM. Cidofovir. Drugs 1996;52:225-230. [PubMed: 8841740]

8. a Shimada N, Hasegawa S, Harada T, Tomisiwa T, Fujii A, Takita T. Oxetanocin, a novel nucleoside from bacteria. J Antibiot 1986;39:1623-1625. [PubMed: 3025147] b Hoshino H, Shimizu N, Shimada $\mathrm{N}$, Takeuchi T. Inhibition of infectivity of human immunodeficiency virus by oxetanocin. J Anibiot 1987;40:1077-1078.

9. a Masuda A, Kitagawa M, Tanaka A, Saito S, Shimada N, Ikeda R, Hoshino H, Daikoku T, Nishiyama Y. Synthesis and antiviral activity of adenosine deaminase-resistant oxetanocin A derivatives-2halogeno-oxetanocin-A. J Antibiot 1993;46:1034-1037. [PubMed: 8344866] b Branalt J, Kvarnstrom I, Classon B, Samuelsson B. Synthesis of [4,5- bis(hydroxymethyl)-1,3-dioxolan-2-yl]nucleosides as potential inhibitors of HIV. J Org Chem 1996;61:3599-3603. [PubMed: 11667204] b Ichikawa E, Yamamura S, Kato K. Synthesis of 2',3'-dideoxy-3'-C-(hydroxymethyl)-4'-thiopentofuranosyl nucleosides as potential antiviral agent. Bioorg Med Chem Lett 1999;9:1113-1114. [PubMed: 10328295]

10. Alder J, Mitten M, Norbeck D, Marsh K, Kern ER, Clement J. Efficacy of A-73209, a potent orally active agent against VZV and HSV infections. Antiviral Res 1994;23:93. [PubMed: 8147583]

11. Nagahata T, Kitagawa M, Matsubara K. Effect of oxetanocin-G, a novel nucleoside analog, on DNAsynthesis by hepatitis B virus virions. Antimicrob Agents Chemother 1994;38:707-712. [PubMed: 7518217]

12. Mansour TS, Storer R. Antiviral nucleosides. Curr Pharm Design 1997;3:227-264.

13. Parks, RE., Jr; Stoeckler, JD.; Cambor, C.; Savarese, TM.; Crabtree, GW.; Chu, SH. Purine nucleoside phosphorylase and 5'-methylthioadenosine phosphorylase: Targets of chemotherapy. In: Sartorelli, AC.; Lazo, JS.; Bertino, JR., editors. Molecular Actions and Targets for Cancer Chemotherapeutic Agents. Academic Press; New York: 1981. p. 229-252.

14. a Nishizono N, Koike N, Yamagata Y, Fujii S, Matsuda A. Nucleosides and nucleotides. 159. Synthesis of thietane nucleosides via the pummerer reaction as a key step. Tetrahedron Lett 1996;42:7569-7572. b Ichikawa E, Yamamura S, Kato K. Synthesis of enantiomerically pure 9-[(1' 
R,2'R,3'S)-bis(hydroxymethyl)thietan-1'-yl] adenine, 3'-thio analog of oxetanocin A. Tetrahedron Lett 1999;40:7385-7388.

15. a Adiwidjaja G, Brunck JS, Polchow K, Voss J. Thiosugars, Part 3 Preparation of methyl 2,3-di- $O$ mesyl-4,6-thioanhydro- $\alpha$-D-galactopyranoside and methyl 2- $O$-mesyl-4,6-thioanhydro- $\alpha$-Dgulopyranoside. Carbohydrate Research 2000;325:237-244. [PubMed: 10839117] b Payre C, Mourabit AA, Merckle L, Ahond A, Poupat C, Potier P. Semisynthesis of D-ring-modified taxoids: thietane derivatives from taxine B. Tetrahedron Lett 2000;41:4891-4894. c Ohuchida S, Hamanaka N, Hayashi M. Synthesis of thromboxane-A2 analog dl-(9,11),(11,12)-dideoxa-(9,11)-epithio(11,12)-methylene-thromboxane-A2. Tetrahedron Lett 1981;22:1349-1352. d Ohuchida S, Hamanaka N, Hayashi M. A convenient route to (+)-(9,11)-epithia-(11,12)-methano-thromboxaneA2 from prostaglandin E2-methyl ester. Tetrahedron Lett 1981;22:5301-5302.

16. Ma T, Pai SB, Zhu YL, Lin JS, Shanmuganathan K, Du J, Wang C, Kim H, Newton MG, Cheng YC, Chu CK. Structure-activity relationships of 1-(2-deoxy-2-fluoro- $\beta$-L-arabinofuranosyl)pyrimidine nucleosides as anti-hepatitis B virus agents. J Med Chem 1996;39:2835-2843. [PubMed: 8709113]

17. Brown B, Hegedus LS. Optically active cyclobutanone chemistry: Synthesis of(-)-cyclobut-A and (+/-)-3'-epi-cyclobut-A. J Org Chem 1998;63:8012-8018.

18. O'Neil IA, Hamilton KM. A novel method for the coupling of nucleoside bases with tetramethylene sulfoxide. Synlett 1992:791-792.

19. Ray AS, Schinazi RF, Murakami E, Basavapathruni A, Shi J, Zorca SM, Chu CK, Anderson KS. Probing the mechanistic consequences of 5-fluorine substitution on cytidine nucleotide analogue incorporation by HIV-1 reverse transcriptase. Antivir Chem Chemother 2003;14:115-125. [PubMed: 14521328]

20. a Schinazi RF, McMillan A, Cannon D, Mathis R, Lloyd RM, Peck A, Sommadossi JP, Stclair M, Wilson J, Furman PA, Painter G, Choi WB, Liotta DC. Selective inhibition of human immunodeficiency viruses by racemates and enantiomers of cis-5-fluoro-1-[2-(hydroxymethyl)-1,3oxathiolan-5- yl]cytosine. Antimicrob Agents Chemother 1992;36:2423-2431. [PubMed: 1283296] b Ma TW, Pai SB, Hu YL, Lin JS, Shanmuganathan K, Du JF, Wang CG, Kim H, Newton MG, Cheng YC, Chu CK. Structure-activity relationships of 1-(2-deoxy-2-fluoro- $\beta$-L-arabino- furanosyl) pyrimidine nucleosides as anti-Hepatitis B virus agents. J Med Chem 1996;39:2835-2843. [PubMed: 8709113] c Lee K, Choi Y, Gllen E, Schlueter-Wirtz S, Schinazi RF, Cheng YC, Chu CK. Synthesis and anti-HIV and anti-HBV activities of 2'-fluoro-2',3'-unsaturated L-nucleosides. J Med Chem 1999;42:1320. [PubMed: 10197975] d Chong Y, Choo H, Chu CK. Effects of fluorine substitution of cytosine analogues on the binding affinity to HIV-1 reverse transcriptase. Bioorg Med Chem Lett 2004;14:437-440. [PubMed: 14698176]

21. Lewis W, Day BJ, Copeland WC. Mitochondrial toxicity of NRTI antiviral drugs: An integrated cellular perspective. Nat Rev Drug Discov 2003;2:812-822. [PubMed: 14526384]

22. Galmarini CM, Mackey JR, Dumontet C. Nucleoside analogues and nucleobases in cancer treatment. The Lancet Oncology 2002;3:415-424. [PubMed: 12142171]

23. Huang H, Chopra R, Verdine GL, Harrison SC. Structure of a covalently trapped catalytic complex of HIV-1 reverse transcriptase: Implications for drug resistance. Science 1998;282:1669-1675. [PubMed: 9831551]

24. Chong Y, Chu CK. Understanding the unique mechanism of L-FMAU(clevudine) against hepatitis B virus: Molecular dynamics studies. Bioorg Med Chem Lett 2002;12:3459-3462. [PubMed: 12419383]

25. a Chong Y, Borroto-Esoda K, Furman PA, Schinazi RF, Chu CK. Molecular mechanism of DAPD/ DXG against zidovudine- and lamivudine- drug resistant mutants: a molecular modeling approach. Antivir Chem Chemother 2002;13:115-128. [PubMed: 12238529] b Lee K, Chu CK. Molecular modeling approach to understanding the mode of action of L-nucleosides as antiviral agents. Antimicrob Agents Chemother 2001;45:138-144. [PubMed: 11120956]

26. Sabini E, Ort S, Monnerjahn C, Konrad M, Lavie A. Structure of human dCK suggests strategies to anticancer and antiviral therapy. Nature Structure Biology 2003;10:513-519.

27. Johansson NG, Eriksson S. Structure-activity relationships for phosphorylation of nucleoside analogs to monophosphates by nucleoside kinases. Acta Biochem Pol 1996;43:143-160.

28. Belen'kii SM, Schinazi RS. Multiple drug effect analysis with confidence interval. Antiviral Res 1994;25:1-11. [PubMed: 7811057] 

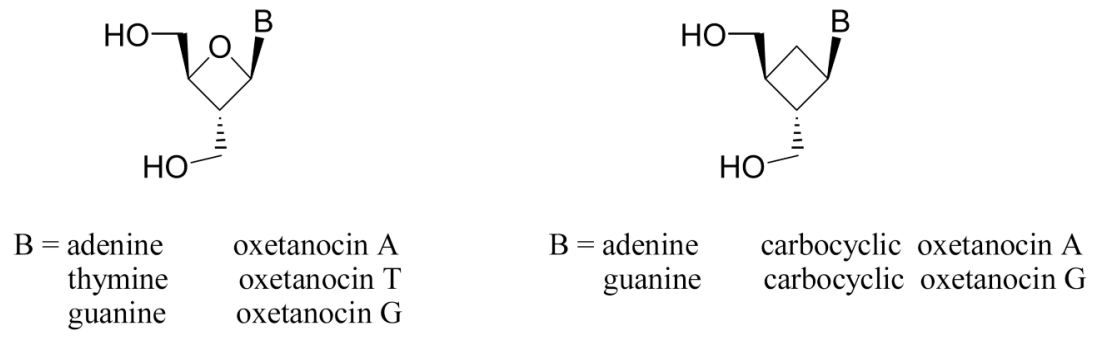

Figure 1.

Oxetanocin A, T \& G and carbocyclic analogs oxetanocin A \& G 


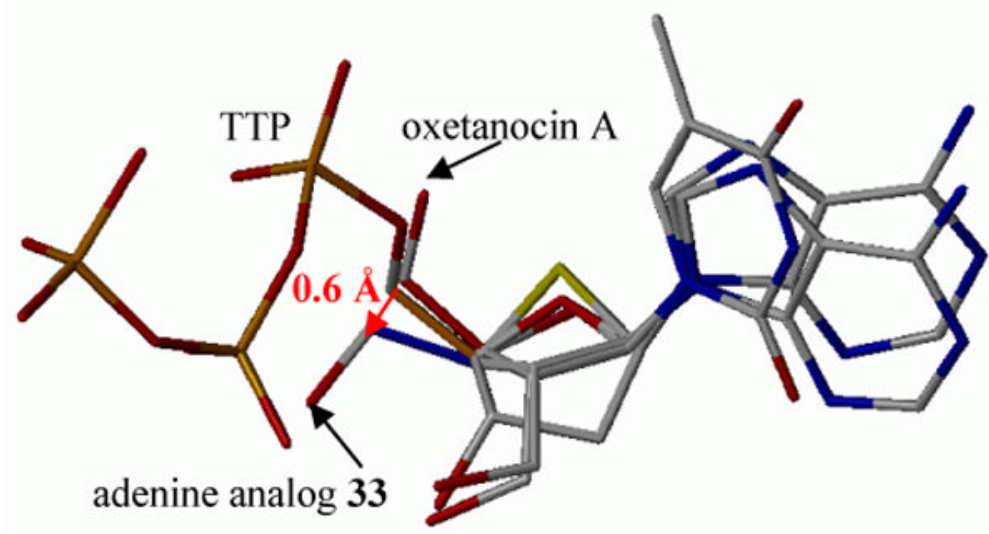

Figure 2.

Superimposed structures of adenosine analog 33 , oxetanocin A and TTP where the C3'-C4' bond in adenosine analog 33 is in blue, the $\mathrm{C}^{\prime}$ - $\mathrm{C} 4^{\prime}$ bond in oxetanocin $\mathrm{A}$ is in red, and the $\mathrm{C} 4^{\prime}-$ C5' bond in TTP is in orange. 

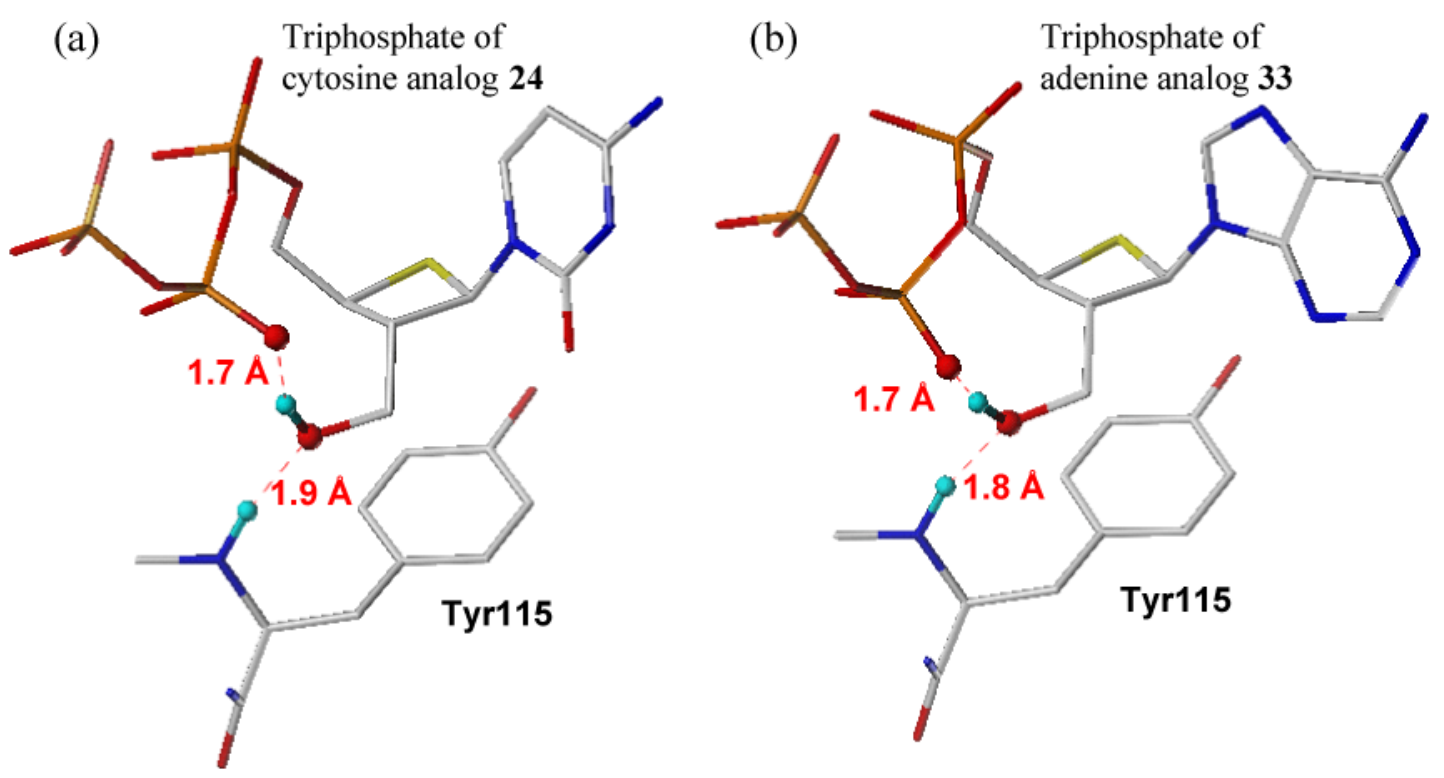

Figure 3.

The minimized structures of HIV reverse transcriptase complexed with (a) the triphosphate of cytidine analog $\mathbf{2 4}$ and (b) the triphosphate of adenosine analog 33 show that both triphosphates are bound to the active site of HIV RT, interacting with Tyr115 and their own $\beta$-phosphate through hydrogen bonding. 
(a)

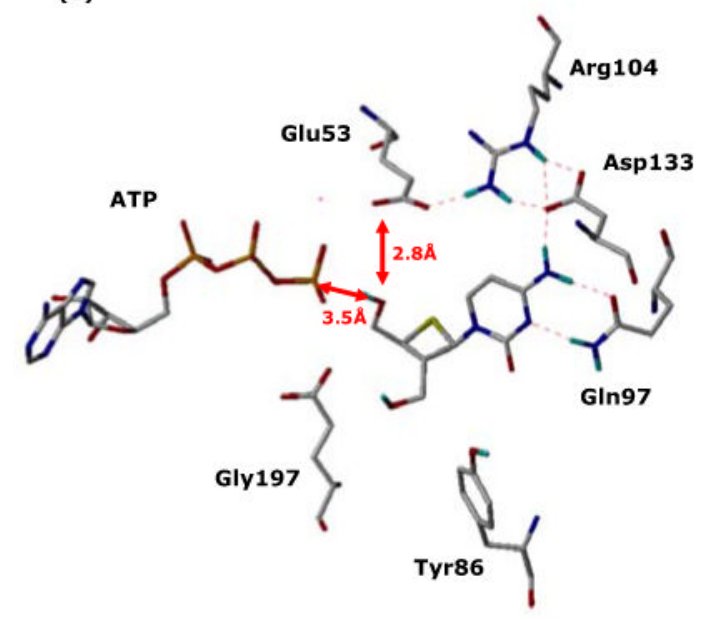

(b)

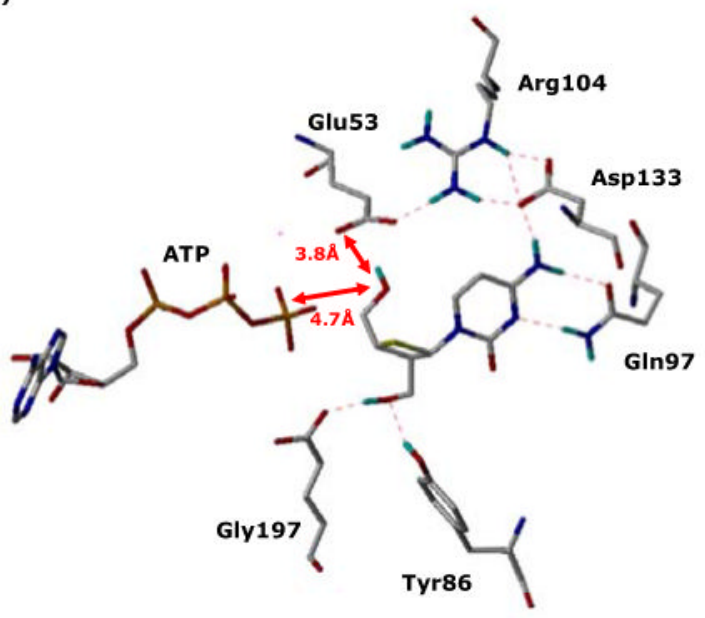

Figure 4.

The minimized structures of deoxycytidine kinase (dCK) complexed with (a) the ${ }_{\mathrm{D}}$-cytidine analog (24) and (b) the ${ }_{\mathrm{L}}$-cytidine analog (52) revealed the increased distance (1.2 $\AA$ ) between the 4'-hydroxyl group and the $\gamma$-phosphate in the case of compound (52) which may be responsible for the lower catalytic efficiency of phosphorylation through the nucleophilic attack. 
(a)

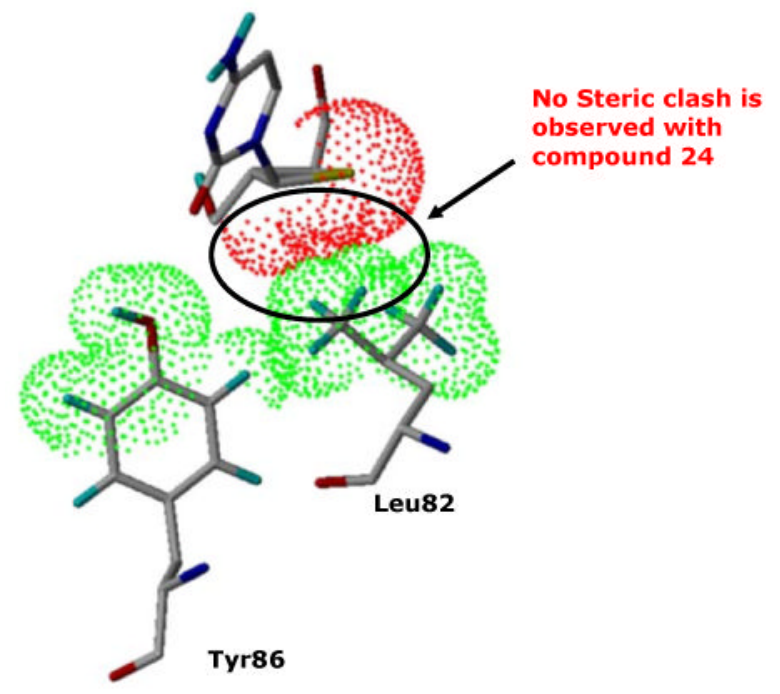

(b)

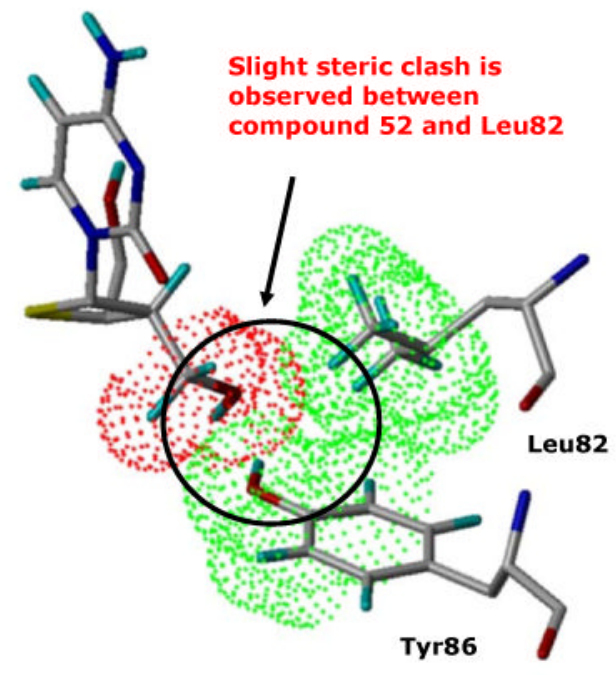

Figure 5.

Steric clashes are observed between compound $\mathbf{5 2}$ and Leu82, but are absent in the case of compound 24. 
<smiles>OC[C@H]1O[C@H]2[C@H](O)O[C@H]1[C@H]2O</smiles>

1<smiles>CC1CCC1C1CSC1C</smiles>

8

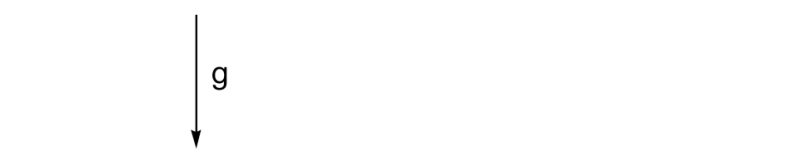

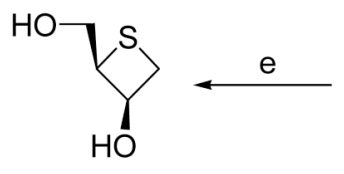

7

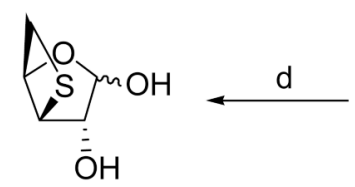

6
AcS

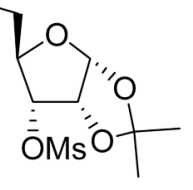

4

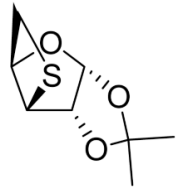

5

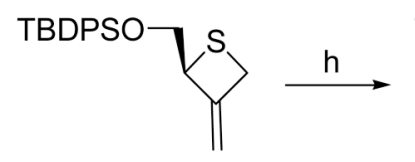

9

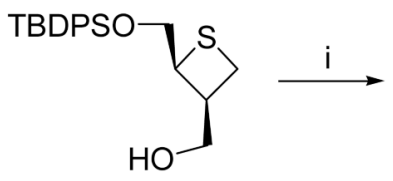

10

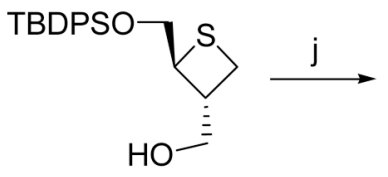

11

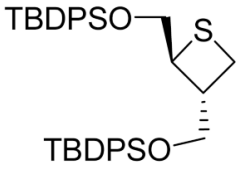

12

Scheme 1.

Synthesis of the key intermediate $\mathbf{1 2}$

a Reagents and conditions: a) $\mathrm{MsCl}$, pyr. DMAP, $\mathrm{CH}_{2} \mathrm{Cl}_{2}$; b) $\mathrm{KSAc}$, DMF; c) $\mathrm{NaHCO}_{3}$, EtOH/ $\mathrm{H}_{2} \mathrm{O}$, reflux; d) $4 \%$ TFA, $\mathrm{OH}^{-}$resin; e) $\mathrm{NaIO}_{4}, \mathrm{NaBH}_{4}$, $\mathrm{MeOH}$; f) TBDPSCl, TEA, DMAP, $\mathrm{CH}_{2} \mathrm{Cl}_{2}$; g) i. $\mathrm{Ac}_{2} \mathrm{O}$, DMSO, ii. Petasis reagent, THF/Et $2 \mathrm{O}(1: 1)$, reflux; h) $\mathrm{BH}_{3} \mathrm{SMe}_{2}$, THF, $\mathrm{H}_{2} \mathrm{O}_{2}, 1 \mathrm{~N} \mathrm{NaOH}$; i) Swern Oxidation, $\mathrm{NaOMe}, \mathrm{MeOH}, \mathrm{NaBH} 4$; j) TBDPSCl, imidazole, $\mathrm{CH}_{2} \mathrm{Cl}_{2}$ 


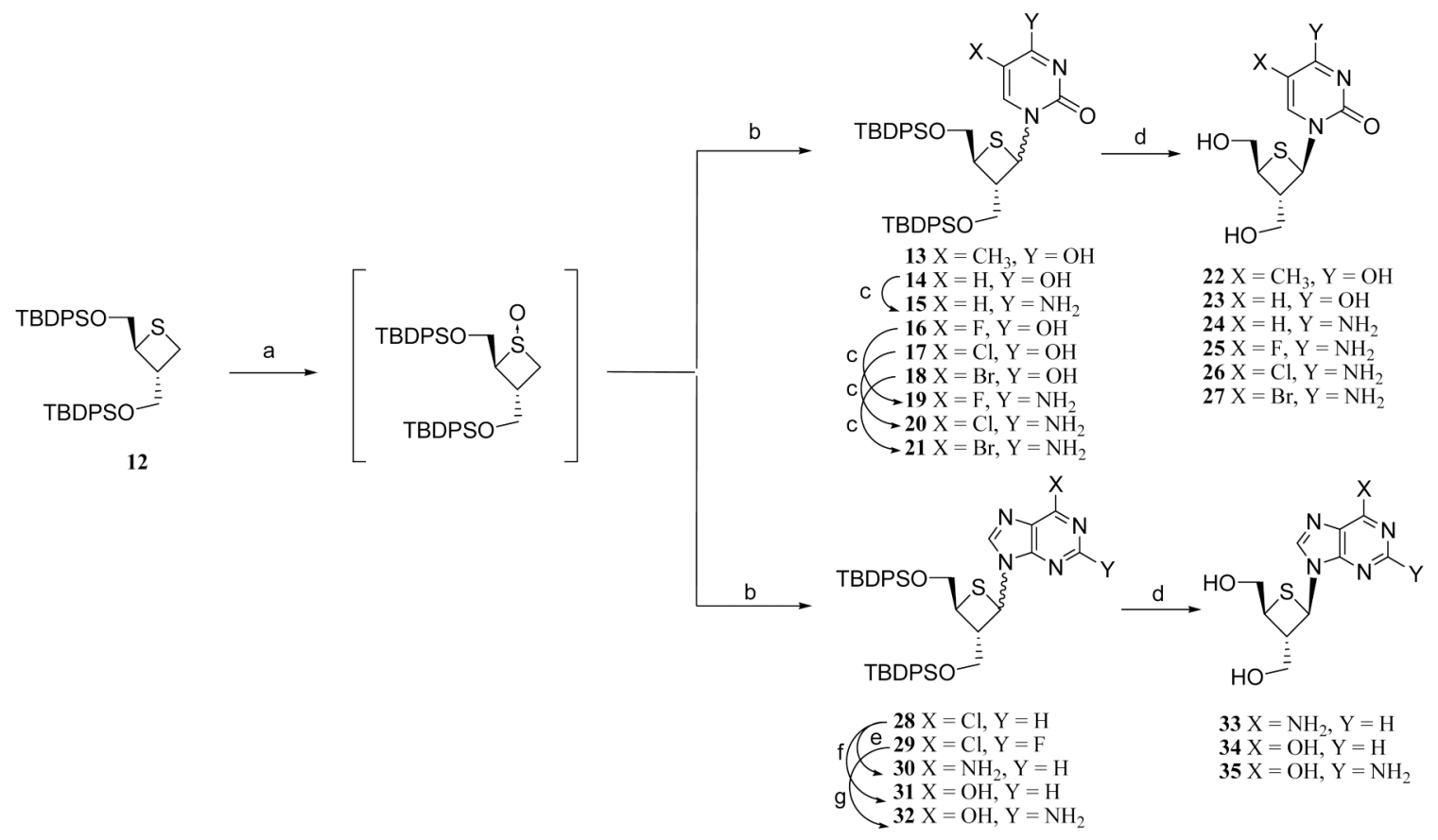

Scheme 2.

Synthesis of ${ }_{D}$-thietanose nucleosides

Reagents and conditions: a) mCPBA, $\mathrm{CH}_{2} \mathrm{Cl}_{2}$; b) pyrimidine or purine, $\mathrm{HMDS}, \mathrm{CH}_{3} \mathrm{CN}$, TMSOTf, TEA, ZnI 2 , toluene; c) 2,4,6-triisopropylbenzenesulfonyl chloride, TEA, DMAP, $\mathrm{CH}_{3} \mathrm{CN}, \mathrm{NH}_{4} \mathrm{OH}$; d) TBAF, THF; e) i. $\mathrm{NaN}_{3}$, DMF, ii. $\mathrm{H}_{2}, \mathrm{Pd}(0), \mathrm{MeOH}$; f) $\mathrm{NaOMe}, 2-$ mercaptoethanol, $\mathrm{MeOH}$; g) i. $\mathrm{NaOMe}, 2$-mercaptoethanol, $\mathrm{MeOH}$, ii. $\mathrm{NH}_{3}, \mathrm{EtOH}, 60^{\circ} \mathrm{C}$, 
<smiles>OC[C@@H]1O[C@@H](O)[C@@H]2O[C@H]1[C@H]2O</smiles>

L-Xylose

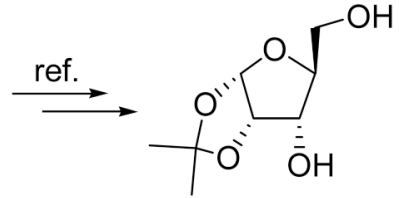

36

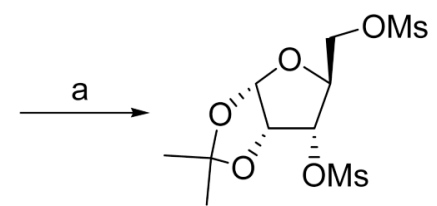

37

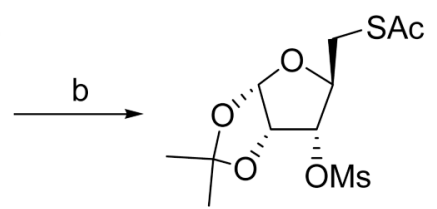

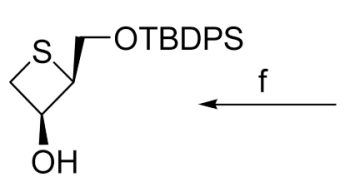

42

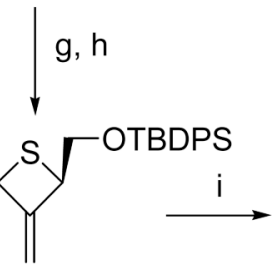

43

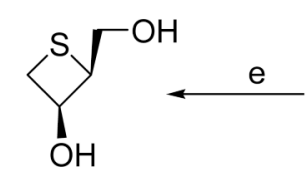

41

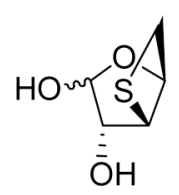

40
38

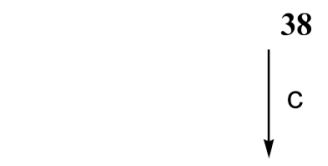

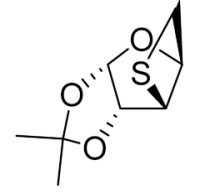

39

Scheme 3.

Synthesis of $\mathrm{L}-3^{\prime}$-thio analogs of oxetanocin A a Reagents and conditions: a) $\mathrm{MsCl}$, pyr. DMAP, $\mathrm{CH}_{2} \mathrm{Cl}_{2}$; b) KSAc, DMF; c) $\mathrm{NaHCO}_{3}$, EtOH/ $\mathrm{H}_{2} \mathrm{O}$, reflux; d) 4\% TFA, $\mathrm{OH}^{-}$resin; e) $\mathrm{NaIO}_{4}, \mathrm{NaBH}_{4}$, $\mathrm{MeOH}$; f) TBDPSCl, TEA, 2,4,6Collidine, $\mathrm{CH}_{2} \mathrm{Cl}_{2}$; g) Ac $2 \mathrm{O}$, DMSO; h) Petasis reagent; i) $\mathrm{BH}_{3} \mathrm{SMe}_{2}$, THF; j) $(\mathrm{COCl})_{2}$, DMSO, $\mathrm{NaOMe}, \mathrm{MeOH}$; k) $\mathrm{NaBH}_{4}, \mathrm{MeOH}$; l) TBDPSCl, imidazole, $\mathrm{CH}_{2} \mathrm{Cl}_{2}$. 


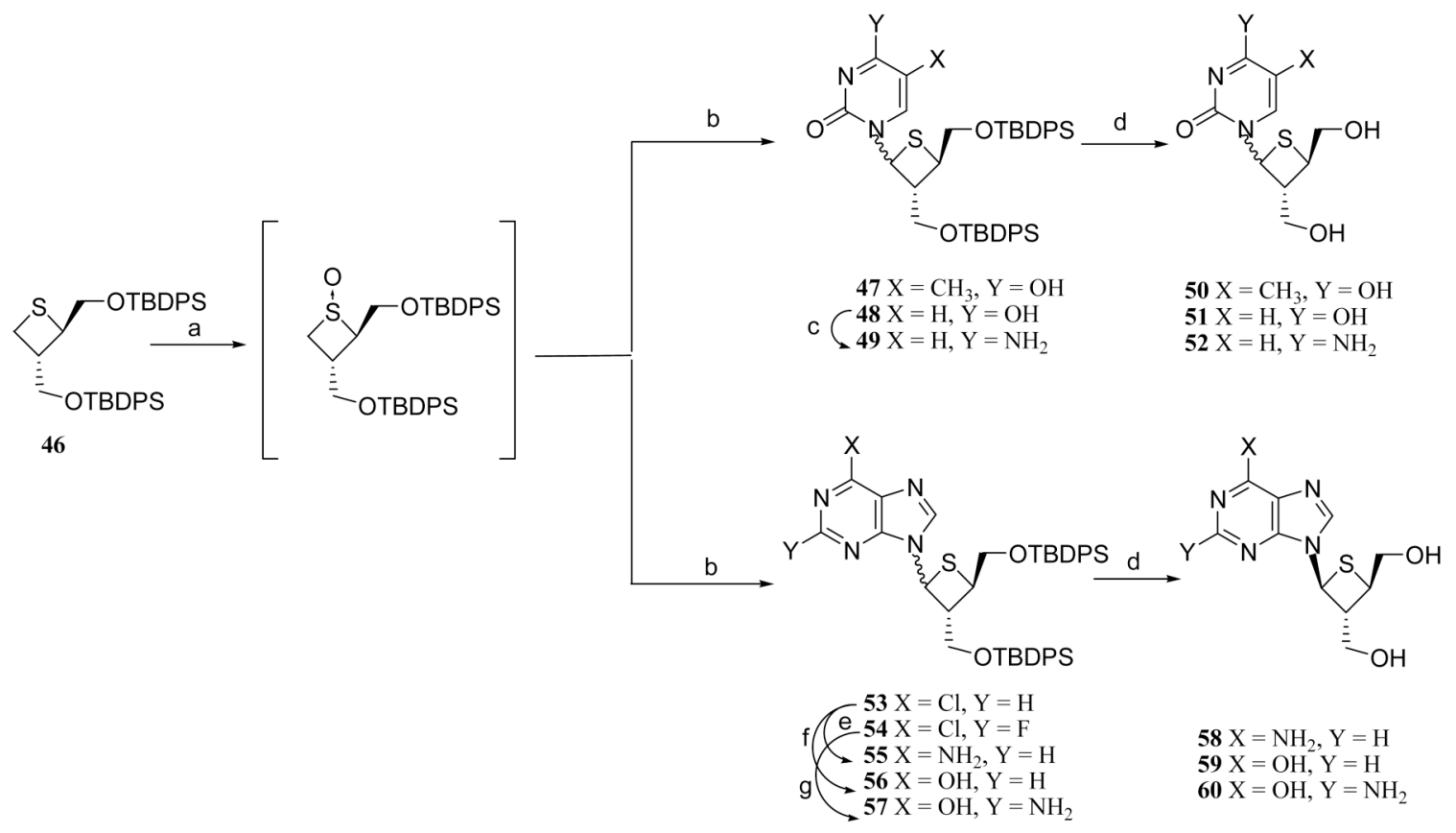

Scheme 4.

Synthesis of ${ }_{\mathrm{L}}$-thietanose nucleosides

Reagents and conditions: a) mCPBA, $\mathrm{CH}_{2} \mathrm{Cl}_{2}$; b) pyrimidine or purine, $\mathrm{HMDS}, \mathrm{CH}_{3} \mathrm{CN}$, TMSOTf, TEA, $\mathrm{ZnI}_{2}$, toluene; c) 2,4,6-triisopropylbenzenesulfonyl chloride, TEA, DMAP, $\mathrm{CH}_{3} \mathrm{CN}, \mathrm{NH}_{4} \mathrm{OH}$; d) TBAF, THF; e) i. $\mathrm{NaN}_{3}$, DMF, ii. $\mathrm{H}_{2}, \mathrm{Pd}(0), \mathrm{MeOH}$; f) $\mathrm{NaOMe}, 2-$ mecaptoethanol, $\mathrm{MeOH}$; g) i. $\mathrm{NaOMe}, 2$-mecaptoethanol, $\mathrm{MeOH}$, ii. $\mathrm{NH}_{3}, \mathrm{EtOH}, 60^{\circ} \mathrm{C}$, 
